\title{
Die Tuberculose des Auges.
}

\author{
Von \\ Dr. O. Haab, \\ Docent der Augenheilkunde in Zärich*). \\ Hierzu Tafel II., III.
}

Man kann die Mittheilung äber die Tuberculose des Auges, welche bis jetzt in der Literatur vorhanden sind, in zwei Gruppen trennen. Die eine Gruppe umfasst die Casuistik der Miliartuberculose der Chorioidea und der Iris, die andere diejenigen Fälle, wo die Tuberculose sich im Bereiche des Auges nicht als Theilerscheinung einer mehr oder weniger allgemeinen Miliartuberculose äusserte.

Die Literatur über die zweite Gruppe ist, namentlich verglichen mit derjenigen der Miliartuberculose der

*) Diese Arbeit wurde im August 1878 als Habilitationssehrift eingereicht und erscheint hicr fast anverändert mit einigen Zasätzen, hauptsächlich einen neuen Fall und Literaturangaben betreffend. 
Chorioidea, eine sehr spärliche, während andererseits diese letztere durch Manz, Cohnheim, v. Graefe u. A. ausgearbeitete und klar hingestellte Krankheitsform die schönen Hoffnungen, welche man anfangs im Interesse der Diagnostik auf sie baute, nur in bescheidenem Maasse rechtfertigte und auch in pathologisch-anatomischer Richtung die Tuberculosenfrage nicht weiter förderte.

Ein viel grösseres Interesse scheint mir zu jetziger Zeit sowohl in klinischer als anatomischer Hinsicht die zweite Kategorie der Erkrankungsfälle zu besitzen. Hierher gehört die Aeusserung der Tuberculose, die man als "locale" zu bezeichnen pflegt, hierher also die Tuberculose der Conjunctiva, die conglobirten Tuberkel der Iris, der Chorioidea ete. Nennen wir diese Erkrankungsform chronische Tuberculose.

Die geringe Zahl der Beobachtungen dieser zweiten Gruppe kann ich um ein beträchtliches vermehren und glaube, dass, wenn einmal das Material auch hier sich etwas gehäuft haben wird, es gelingen dürfte, diese sonderbaren Processe, die scheinbar so wenig mit dem, was man sonst Tuberculose nennt, zu thun haben, besser zu verstehen, namentlich im Zusammenhang mit der ganzen Individualität des Betroffenen.

So viel steht fest, dass die Tuberculose, wie sie sich im Bereich des Auges äussert, je länger je mehr an Wichtigkeit gewinnt und vielleicht auch hier wieder, wie schon mehrmals (Entzündung, Regeneration etc.) das Auge der Ort sein wird, wo die experimentelle Pathologie einen alten Streit schliesslich zum Austrag bringt.

Unter den elf Fällen von Tuberculose des Auges, die ich anatomisch untersucht habe, war 6 Mal die Conjunctiva, $4 \mathrm{Mal}$ die Iris, $1 \mathrm{Mal}$ die Conjunctiva bulbi und Chorioidea zagleich der Sitz der Neubildung. Diesen mikroskopisch untersuchten Fällen werde ich dann noch 
eine Anzahl nur klinisch beobachteter Krankheitsfälle anreihen. - Von den elf anatomisch untersuchten Fällen verdanke ich neun der Güte von Herrn Prof. Horner, zwei überliess mir freundlichst Herr Prof. Graefe in Halle. Für die klinischen Beobachtungen bin ich ebenfalls Herrn Prof. Horner zu Dank verpflichtet, indem ich dieselben seinen Kranken - Protocollen entnehmen durfte. Einen Fall habe ich selbst beobachtet.

I. Die Tuberculose der Conjunctiva.

Die sieben bis jetzt anatomisch untersuchten und veröffentlichten Fälle von Tuberculose der Conjunctiva*) zeigten, dass, ähnlich wie eine Synovialmembran auch die Conjunctiva von einem Process befallen werden kann, der sich durch starke Granulationsbildung auszeichnet, wobei wie dort die Granulationen als Träger von $\mathrm{Tu}$ berkelknötchen erscheinen. Ich möchte aber an der Hand meiner sechs Fülle hervorheben, dass die Tuberculose der Conjunctiva sich nicht etwa mit einem Process auf gleiche Linie stellen lässt, wie er z. B, in einer beliebigen Wunde eine reichliche Granulationswucherung anfacht, sondern dass wir hier ein Krankheitsbild von

*) Köster, Centralbl. f. d. med. Wissensch. 1873.

Sattler, Irish-Hospital-Gazette, 1874.

W alb, klin. Monatsbl. f. Augenheilk. 1875, pag. 257.

1877, pag. 285.

1878, August.

Herter, Charité - Annalen 1875, 11. Jahrg., pag. 523.

Sattler, Bericht über die Heidelberg. Versamml. Klin. Monatsbl. f. Augenheilk. XV. Jahrg., pag. 66 u. 67.

Die tuberculose Natur der beiden von Hock mitgetheilten Fälle (klin. Monatsbl. 1875, pag. 309) lässt sích stark anfechten. 
ganz specifischem Charakter vor uns haben, dass wir es namentlich sehr häufig nicht mit einem localen Vorgang an der Conjunctiva allein zu thun haben, sondern mit der Aeusserung einer, das ganze Individuum beherrschenden Disposition: der Scrophulose resp. Tuberculose. Bei den typischen Fällen von Conjunctivaltuberculose nämlich, und dies ist in erster Linie zu erwähnen, nimmt der Lymphapparat der Umgebung des Auges in hohem Grade an der Erkrankung Theil und zwar so, dass, wenn z. B. das linke Auge erkrankt, zugleich auch oft ganz acut eine Schwellung der Lymphdrüsen vor dem linken Ohr, unter dem linken Kieferwinkel und bis gegen das Kinn hin auftritt. Ich will gleich hier schon bemerken, dass bei der chronischen Tuberculose der Iris häufig ganz dasselbe der Fall ist. Auch in dem ersten der von Walb publicirten Fälle von Tuberculose der Conjunctiva fanden sich am Ohr und Hals derselben Seite mächtige Lymphdrüsenschwellungen. Diese Vergrösserung der gleichseitigen Lymphdrüsen kann die längste Zeit unilateral bleiben, wie auch die Conjunctivitis tuberculosa meist nur das eine der beiden Augen befällt. Offenbar ist also die Tuberkelwucherung in der Conjunctiva Theilerscheinung einer Erkrankung des Lymphapparates der betreffenden Kopfhälfte. Dafür, dass ein simpler Catarrh das primäre und die dann auf Grund scrophulöser Disposition auftretende Granulationswucherung und Schwellung der Lymphdrüsen secundärer Natur seien, konnte ich aus meinen Fällen keine genügenden Anhaltspunkte gewinnen.

Die Annahme aber, es sei die Drüsenschwellung bloss Folge eines chronischen, vielleicht scrophulösen Catarrhes der Bindehaut, scheint mir nicht gerechtfertigt, namentlich den vielen Fällen gegenüber, wo wir bei lange dauernden, ekzematösen Conjunctiviten und Keratiten trotz des langen Reizzustandes häufig eine 
Drüsenschwellung gar nicht auftreten sehen. - Es schien vielmehr, als trete bei der Tuberculose mit einem Schlag, wie etwas zusammengehöriges die Schwellung der Drüsen und die Verdickung der Lider auf, ohne dass das betreffende Auge vorher wesentlich erkrankt gewesen.

Präsentirt sich uns dann der - gewöhnlich noch in jüngeren Jahren befindliche - Patient, so fällt vor allem die starke Verdickung eines oder beider Lider des einen Auges auf. Ist der Process z. B. in der Conjunctiva des oberen Lides einigermassen stark entwickelt, so ist dies obere Lid um das $3-4$ fache verdickt und hängt über das untere Lid herab. Dem Patienten ist es nicht möglich, dieses Auge zu öffnen. Die Cutis der Lider und Umgebung ist etwas geröthet und von einzelnen ausgedehnten Gefüssen durchzogen. Die Lidgeschwulst fühlt sich weich und elastisch an. Beim Ectropioniren des Lides wälzt sich dann die mit massenhaften, üppigen Granulationen besetzte Conjunctiva hervor, ganz einer dicht granulirenden Wundfläche oder Synovialis gleich. Da, wo die Granulationen noch jung, intact sind, haben sie eine scharlach- bis grau - rothe Färbung. Stellenweise und bei längerem Bestehen zerfallen sie und es bilden sich durch oberflächliche Usur unebene, gelbrothe, speckig aussehende geschwürartige Flächen. Eine fernere Eigenthümlichkeit der Wucherungen besteht darin, dass dieselben durch den Druck gegen den Bulbus abgeplattet, eine mässig höckerige Oberfläche, dagegen manchmal ziemlich tiefe Zerklüftung zeigen und dass diejenigen, welche nahe der Uebergangsfalte und auf derselben ihren Sitz haben, sich hahnenkammförmig in den Fornix hineinschmiegen. $\mathrm{Zu}$ bemerken ist, dass die Conjunctiva im Bereich des Tarsus vollständig, sowohl am oberen als am unteren Lid von den Granulationen frei bleiben kann und dass dann die Wucherungen ganz allein von der Uebergangsfalte aus- 
gehen (s. Fall V.), wobei die Conjunctiva tarsi eine sammetartige papilläre Schwellung zeigt. Auch in den Fällen, wo bloss das obere Lid von der Affection betroffen, ist die Conjunctiva des unteren Lides diffus geschwellt, zeigt sammetartige, stark geröthete Oberfläche. Eine stark eitrige Secretion ist die unangenehme Zugabe zu dieser im Uebrigen schmerzlosen Affection der Bindehaut. Die Schmerzlosigkeit ist der Grund da* für, dass gewöhnlich die Patienten erst längere Zeit nach Beginn des Uebels Hülfe beim Arzt suchen, weshalb ich auch über die Anfangsstadien der Erkrankung anatomisch nichts sicheres anzugeben im Stande bin.

Oeffnet man das afficirte Auge so, dass die Conjunctiva bulbi und die Cornea zu Tage tritt, so bemerkt man an ersterer bloss eine etwas stärkere Füllung der Gefässe und die Cornea ist in den Fällen, wo die Conjunctival-Wucherungen nahe dem Fornix sitzen, gewöhnlich intakt. Wenn sich dagegen die Granulationen auch über die Tarsalconjunctiva ausgebreitet haben, so tritt gern oberflächlicher (Reibungs.) Pannus auf (s. Fall I.).

Höchst frappant ist der Umstand, dass in zwei von den sechs Fällen - vielleicht sogar noch in einem dritten - anch die Schleimhant des Thränensackes Sitz solcher Granulationen war. Eine starke Schwellung der Thränensackgegend verräth dies und schneidet man etwas ein, um den vermeintlichen Eiter zu entleeren, so zeigt es sich, dass gar kein oder nur sehr wenig eitriges Secret da und die ganze Geschwulst durch die granulös wuchernde Schleimhaut des Thränensackes producirt war (s. Fall I. u. VI.). Es bleibt dann nichts übrig, als den Thränensack auszukratzen. - Auch in dem Köster'schen Falle von tuberculösen Wucherungen auf der Conjunctiva war eine Blenorrhoe des Thränensackes vorhanden (nach mündlicher Mittheilung an Walb, Walb, klin. Monatsbl. 1875, pag. 261). Die Ansicht von 
Walb, dass das "Granulom" der Conjunctiva durch Blenorrhoe des Thränensackes verursacht werden könne, ist aber kaum richtig, denn sonst müssten bei der grossen Zabl der Patienten mit Thränensackblenorrhoe diese "Granulome" häufiger sein. Es war vielleicht auch in dem Falle von Köster die Schleimhaut des Thränensackes mit betheiligt. Im ersten unten genauer geschilderten Krankheitsfalle vollends ist die Conjunctiva rechts und der Thränensack links tuberculös erkrankt, also ein Zusammenhang im Sinne von Walb unmöglich.

Dies ist in Kurzem das Bild der häufigeren Form der Conjunctival-Tuberculose. Seltener ist die Conjunctiva bulbi Sitz einer Tuberkeleruption*), wird sie aber davon befallen, so tritt die Granulationsbildung etwas zurück und es fällt in erster Linie, namentlich, wenn die Erkrankung nicht schon sehr lange gedauert hat, die Tuberkelinfiltration als solche auf, indem dann die disseminirten graulich - durchscheinenden Knötchen alsbald die Vermuthung anf Tuberkel lenken und diese nicht erst, versteckt in dem Granulationsgewebe, mit dem Mikroskop aufgesucht werden müssen.

In sämmtlichen sechs Fällen, deren Schilderung ich unten folgen lasse, habe ich excidirte Stücke der gewueherten Schleimhaut mikroskopisch vermittelst einer grossen Zahl von Schnitten untersucht. Der mikroskopische Befund ist, trotz des verschiedenen Alters der Patienten, des makroskopisch etwas differenten Aussehens der Wucherungen im einen oder anderen Falle in allen sechs Fällen ein auffallend übereinstimmender. Wechselnd ist bloss das Verhältniss zwischen eigentlichem Tuberkelgewebe und Granulationsgewebe. Letzteres uberwiegt da, wo schon mit localen, medicamen-

*) Sattler. Klinische Monatsbl., Jahrgang XV., Beilage-Heft, pag. 66.

Ferner: Krankengeschichte Nr. 19. 
tösen Eingriffen gegen die Affection zu Felde gezogen worden war. Da tritt das Tuberkelgewebe vor dem üppig wuchernden Granulationsgewebe zurück; dieses nimmt die oberflächlichen Partien ein, wïhrend die Tuberkelknötchen mehr in den tieferen Schichten nahe dem Tarsus sich finden und die Hauptmasse der Wucherungen besteht dann aus stark vascularisirtem, kleinzelligem, gewöhnlichem Granulationsgewebe. Wo aber ein frischer Fall, der noch nicht cauterisirt worden, zur Untersuchung benützt werden kann, da überwiegt die tuberculöse Neubildung so, dass es schwierig wäre, die Knötchen mit ihrer typischen Anordnung der Elemente zu übersehen. Sie sind hier durch die ganze abnorme Schleimhautpartie zerstreut, man findet sie nahe der Oberfläche ebenso wie in der Nähe des Tarsus. Bald stehen die einzelnen Tuberkelknötchen gruppenweise beisammen und bilden so grössere und kleinere Knoten und unregelmässige Tuberkelinfiltrate, bald sind sie nur vereinzelt $\mathrm{zu}$ treffen und entbehren in letzterem Falle häufig der Riesenzellen oder eines Käseheerdes im Centrum. Uebrigens ist auch bei den grösseren Knötchen das Vorkommen einer oder mehrerer central gelegener Riesenzellen durchaus nicht Regel, sondern es kann dies bloss als sehr häufiger Befund bezeichnet werden. So wenig als bei anderweitig vorkommenden Tuberkeln findet man hier in jedem Knötchen eine Riesenzelle. Abgesehen davon, dass diese zufällig ausser den Schnitt fallen kann, giebt es offenbar legitime Tuberkelknötchen, die derselben einfach entbehren. Das Postulat, ein jeder Tuberkel müsse auch eine Riesenzelle führen, geht zu weit, es giebt Tuberkel ohne Riesenzellen. Es giebt ferner solche, und gerade bei der Conjunctivaltuberculose beobachtete ich dieselben häufig, die statt einer oder mehrerer Riesenzellen im Centrum einen dicht gedrängten Haufen kleiner Kerne 
besitzen (s. Tafel II., Fig. 5). Diese Kerne haben keine Aehnlichkeit mit den zart contourirten, meist ovalen, sich mit Hämatoxylin schwach färbenden Kernen der Riesenzellen. Sie färben sich vielmehr intensiv schwarzblau, liegen ganz dicht auf und in einander und sind, wie bei stärkerer Vergrösserung deutlich $\mathrm{zu}$ sehen ist, in lebhafter Theilung begriffen. Auch sind sie anscheinend klein, kleiner fast, als die der farblosen Blutkörperchen und vollends viel kleiner als die der umliegenden epitheloiden Zellen des Tuberkels. Diese sonderbaren, nur im Centrum eines Tuberkelknötchens vorkommenden Kernhaufen trifft man im Ganzen nur selten, aber in fast allen Fällen von Conjunctival-Tuberculose habe ich sie jetzt $a b$ und $z u$ constatirt. Diese Kernhaufen bilden den directesten Gegensatz zu den Gebilden, die man als Riesenzellen zu bezeichnen pflegt. Die rege Kernproliferation contrastirt aufs Lebhafteste mit der gleicbsam versteinerten Ruhe der Riesenzelle. Denn so viele der letzteren ich auch, sei es im Knochen, im Sarcom oder Tuberkel schon untersuchte, ich habe nur äusserst selten die Kerne einer Riesenzelle in Theilung begriffen gesehen. Nie erhielt ich Bilder, aus denen ich hätte den Schluss ziehen dürfen, dass die manchmal so grosse Zahl der Kerne einer einzelnen Riesenzelle Product von Kerntheilung innerhalb dieser Riesenzelle selbst sei. Nach Ziegler*) bildet sich eine Riesenzelle so, dass eine besonders lebenskräftige Zelle (farbloses Blutkörperchen) die umliegenden Zellen in sich aufnimmt, die Kerne derselben aber nicht verwendet (indem diese zu Grunde gehen), sondern entsprechend der Protoplasmazunahme neue Kerne durch fortgesetzte Theilung des ursprünglichen Kernes der

*) Ziegler. Experimentelle Untersuchungen über die Herkuntt der Tuberkelelemente. Würzburg 1875. 
betreffenden, lebenskräftigen Zelle schafft. „Die Kerne (der Riesenzelle) stammen also von einem (Keln) ab und ist dadurch in dieser Hinsicht die Abstammung der Riesenzelle von einer einzigen Zelle gesichert" (pag. 59). Weun dies bei den Riesenzellen des Tuberkels wirklich so wäre, müsste man an den Kernen dieser Riesenzellen doch irgendwie durch Finschnürung oder beginnende Abschnürung eine Vermehrung durch Theilung oder Sprossung angedeutet sehen. Aber nichts von alledem. Die Bilder, welche Ziegler zwischen den Glasplättchen erhielt, ähneln mehr der regenerativen Proliferation, wie sie namentlich von $\mathrm{Eberth}$ eingehend geschildert wurde und können meiner Ansicht nach nicht ohne Weiteres auf den Tuberkel übertragen werden. Die Riesenzelle des Tuberkelknötchens scheint mir vielmehr ihre Entstehung dem Confluiren einer grösseren oder kleineren Zahl von epitheloiden Zellen sammt den Kernen zu verdanken, ähnlich wie v. Ewetzky*) dies für die grossen Riesenzellen annahm, die er auf den in die vordere Kammer eingefübrten Glimmerplättchen fand (pag. 101).

Wenn man beim Tuberkel die Kerne der Riesenzellen mit denjenigen der zunächst sie umgebenden epitheloiden Zellen vergleicht, so ist die Differenz in Grösse, Form, Färbung durch Hämatoxylin meist eine sehr geringe, ja verschwindend kleine und die Annahme, dass die Kerne der Riesenzellen ursprünglich epitheloiden Zellen angehörten, gewinnt an Wahrscheinlichkeit. Da die Zellproliferation in den peripheren Partien des Tuberkels am stärksten ist, wird sich innerhalb des Tuberkelknötchens das Bestreben eines centripetalen Schubes der einzelnen Zell - Elemente gewiss geltend

*) Ueber das Endothel der Membrana Descemeti. Unter. snchungen ans dem pathologischen Institut au Zürich. Herausgeg. von Eberth. Heft III. 
machen, wenn die Vitalität des ganzen Processes einigermassen kräftig ist. Sonach kann man sich, rein mechanisch, die Verhältnisse so vorstellen, dass da, wo der Druck am stärksten - im Centrum des Tuberkels zuerst einige der epitheloiden, membranlosen (Schü p$\mathrm{pel}^{*}$ ) Zellen verschmelzen und dass dann in diesen Protoplasmahaufen hinein successive noch mehr Zellen hineingedrängt werden sammt ihren Kernen. Diese letzteren bleiben bestehen, ohne zu proliferiren; sind ja doch diese dem Centrum des Knötchens am nächsten liegenden epitheloiden Zellen zugleich die ältesten. Riesenzellen mit darin eingeschlossenen ganzen Zellen habe ich auch im Tuberkel ab und zu getroffen, ähnlich dem Bild, das Ziegler Tafel IV., Fig. 7 giebt.

Uebrigens möchte mir, nach allem, was ich am Knochen gesehen habe, der eben erwähnte Modus der Entstehung auch für die sogenannten Osteoklasten nicht unwahrscheinlich vorkommen. Denken wir uns z. B. einen Hohlraum der Spongiosa in einem entzündeten Knochen. Der von starren Knochenwandungen grösstentheils umschlossene Markinhalt erfährt durch Emigration, seröse Durchtränkung und nach einiger Zeit auch durch Proliferation der Markzellen eine Volumszunahme. Dadurch werden offenbar die dem Knochen zunächst liegenden Zellen, da sie nicht ausweichen können, aneinander gepresst und die Möglichkeit, dass je eine Anzahl zu einer mehrkernigen Zelle verschmilzt, rein in Folge der mechanischen Verhältnisse, ist sehr nahe liegend. $0 \mathrm{~b}$ die Osteoklasten dann auf eigene Faust den Knochen angreifen oder ob sie bloss das Zeichen dafür sind, dass dort von Seiten des Markes ein erhöhter expansiver Druck auf den Knochen ausgeübt wird, muss vor der Hand dahin gestellt bleiben and berührt auch unser vorliegendes Thema nicht näher.

Uebrigens stimmen auch die Resultate der experimentellen Untersuchungen von Giovanni Weiss*)

*) Untersuch. über Lymphdrüsentuberculose, pag. 85.

**) Virchow's Archiv, Bd. 68, pag. 59. 
vollständig überein mit obiger aus der blossen Betrachtung der Thatsachen abstrahirten Ansicht von der Entstehung der Riesenzellen. Nur glaube ich nicht, dass, wie Weiss annimmt, die Reizung der Zellen (Granulationszellen nach Weiss) durch den Fremdlörper genügt, um das Verschmelzen derselben zu Riesenzellen zu Stande zu bringen. Die Wirkung des Fremdkörpers ist wohl bloss die, das umliegende Gewebe in toto zu reizen, Auswanderung und Proliferation (regenerative) zu veranlassen, worauf dann um den unnachgiebigen Fremdkörper herum die Zellen durch Druck von allen Seiten her zur Verschmelzung gebracht werden.

Es giebt hier offenbar ein Grenzgebiet, wo die regenerative Proliferation, die auf Kernvermehrung durch Theilung (und vielleicht auch endogene Kernbildung) basirt und die mehr scheinbare Proliferation, wie wir sie bei den Riesenzellen sehen, in einander übergehen. Die Riesenzellen um Fremdkörper herum neigen mehr zu der zweiten Categorie und diese ganze Categorie ist durch die Vergänglichkeit, den regressiven Charakter des Riesenzellproductes gekennzeichnet (vergl. Giovanni Weiss, loc. cit., pag. 73 und v. Ewetzky, loc. cit., pag. 101). Es tritt bei diesen Gebilden bald fettiger Zerfall ein und das gleiche ist bei den Riesenzellen des Tuberkels der Fall. Wo wir in einem grossen Protoplasmahaufen nicht Kerne sehen, die durch Einschnürung, Vermehrung der Kernkörperchen etc. auf eine Kernproliferation hindeuten oder wenn wir nicht endogene Kernbildung nachweisen können, dürfen wir annehmen, dass dieses Protoplasma der regressiven Metamorphose entgegengeht, die sich auch bald, wie wir im Tuberkel sehen, durch Vacuolenbildung ankündigt.

Was die endogene Kernbildung betrifft, so will ich nicht läugnen, dass man hier und da Riesenzellen findet, die auf diese Art neue Kerne zu produciren scheinen. 
Aber ganz überzengende Bilder, die für endogene Kernbildung sprechen würden, habe ich doch nicht erhalten können und namentlich habe ich mich nicht davon überzeugen können, dass diese in Frage stehenden kleineren, zarter gefärbten Kerne nicht auch von den epitheloiden Zellen abstammen, welche ja $a b$ und zu ganz ähnliche zarte Kerne besitzen.

$\mathrm{Zu}$ ähnlichen Ansichten gelangten bezüglich der Genese der Riesenzellen Charcot und Gombault: "Sur la structure et le mode de développement des cellules géantes dans le tubercule"*). Ch, und G. schlugen bei ihrer Untersuchung den umgekehrten Weg ein wie Giovanni Weiss. Sie isolirten eine Riesenzelle und zerlegten dieselbe dann unter dem Mikroskop durch Druck auf das Deckgläschen in ihre Elemente. Es gelang ihnen auf diese Weise von der Zelle, die zahlreiche Protoplasmaausläufer besass, eine Anzahl Zellen abzulösen, die einen oder mehrere Kerne und eine Anzahl der erwähnten Protoplasmafortsätze besassen. "Diese Zellen sind nach ihrer vollständigen Isolirung leicht als epitheloide Zellen zu erkennen, die verschmolzen gewesen mit der Riesenzelle. Letztere ist jetzt um ebensoviel verkleinert."

Die so verkleinerte Riesenzelle besitzt aber immer noch eine grosse Zahl Protoplasmaausläufer, die aber nicht mehr auf erwähnte Art abgetrennt werden können. Verstärkt man den Druck, so kann man in gewissen Fällen die Riesenzelle sich in eine Anzahl kleinerer Theile auflösen sehen, die mehrere Kerne besitzen und deren ZelIstructur man nicht bezweifeln kann. - Im Ferneren schildern nun $\mathrm{Ch}$. und G. die Structur einer Riesenzelle an der Hand von drei durch dieselbe gelegten successiven Schnitten. Es ergiebt sich hieraus,

*) Le Progrès médical 1878, No. 34, pag. 656. 
dass das Centrum der Riesenzelle frei von Kernen ist und diese sich nur in der Randschicht befinden $u$. s. w. Diese periphere, kernhaltige Zone ist lediglich aus verschmolzenen Zellen zusammengesetzt, aber diese Zellelemente haben eine Veränderung erlitten, die durch theilweises Verschmelzen des Protoplasma's ein gegenseitiges Verkleben bewirkte." Diese Modification, die das Verschmelzen der Zellen ermöglicht, besteht in einer Aufquellung des Protoplasma, wobei es stark granulirt wird. Derselbe Process führe zur Bildung der epitheloiden Zellen des Tuberkels. Auch die Endothelzellen der Lungenalveolen verfallen unter Umständen, indem sie abgestossen werden (Desquamativ pneumonie?) dieser Metamorphose und in gleicher Weise die Endothelzellen der Gefässe von gewisser Grösse. Ch. und G. neunen diese Veränderung des Protoplasma "transformation vitreuse." Diese sei es, welche die spätere Verkäsung einleite. Das Centrum der Riesenzelle, das Anfangs aus einem Haufen Zellen bestanden habe, die dann dieser "transformation vitreuse" anheimfielen, sei schon in Ver. käsung begriffen. Die Randzone zeige die glasige Umwandlung des Protoplasma und während so die käsige Umänderung centrifugal fortschreite, verschmelzen in der Peripherie immer wieder neue epitheloide Zellen.

Meine oben geäusserte Ansicht von der Entstehung der Riesenzellen erhält durch die Beobachtungen von Ch. und G. eine neue Stütze, wenigstens in manchen Punkten. Aber in einem Punkte muss ich den Erörte. rungen dieser Autoren $Z$ weifel entgegensetzen. Sie sagen, indem sie die glasige Metamorphose der Zellen schildern: „Die Zellen nehmen an Grösse zu, und während ihre Kerne proliferiren, verändert sich das Protoplasma in erwähnter Weise" (wird glasig). Erstens scheint es mir unwahrscheinlich, dass in einer Zelle, die auf besagte Weise degenerirt, noch Kernproliferation 
stattfindet. Zweitens habe ich eben nirgends, auch in den den Riesenzellen zunächst liegenden epitheloiden Zellen Kernproliferation nachweisen können und bin aus eben diesem Grund zu meiner Anschauung von der Genese der Riesenzellen gelangt and habe die Ansicht von Schüppel, Ziegler u. A, dass bei der Bildung der Riesenzellen Kerntheilung thätig sei, bestritten. Einen Beweis dafür, dass die in glasiger Metamorphose begriffenen Zellen Kerntheilung aufweisen, liefern übrigens Ch. und G. nicht und scheinen dies mehr auzunehuen.

Kehren wir nach dieser Abschweifung auf das Gebiet der Riesenzellen Theorie zum Ausgang;punkt, den dichten Haufen kleiner Kerne, die sich hier und da im Centrum von Tuberkeln finden (Fig. 5), zurück, so stehen dieselben mit dem uben von ler Riesenzelle Gesagten schlecht im Einklang. Statt der trägen Confluenz der epitheloiden Zellen zu einer Riesenzelle, haben wir eine üppige Proliferation gerade da, wo es am wenigaten zu erwarten ist. I'h gestehe, dass mich dieser Befund auch Anfangs, besonders seiner relativen Häufigkeit wegen, frappirte. Er lässt sich nämlich nicht anders deuten, als durch die Annahme, dass eine Anzahl Granulationszellen durch starke Kernvermehrung hier inmitten des Tuberkels die Kernhaufen producirten. Denn vereinzelte wandernde Granulations - resp. Bindegewebszellen nebst weissen Blutkörperchen trifft man ja gewöhnlich auch in den centralen Partien der Tuberkel. - Man möchte versucht sein, in besagten Kernhaufen das Zeichen einer güustigen Metamorphose des Tuberkels im Granuliationsund Bindegewebe, statt im Käse zu erblicken. Dass die Kernhaufen etwa nach einiger Zeit rasch zerfallen und die Verkäsung begünstigen, konnte ich nämlich nie wahrnehmen, ebensowenig, dass etwa aus ihnen sich Riesenzellen formiren. Dürften wir diesen Kernconglov. Graefe's Archiv für Ophthalmologie, XXV. 4. 
meraten die eben erwähnte Bedeutung vindiciren, so wäre dies sehr erfreulich. Denn verschiedene Thatsachen legen die Vermuthung nahe, dass die Tuberkel, wenn auch vielleicht bloss local, ausheilen können. Wir werden namentlich weiter unten beim Granulom der Iris sehen, dass wir fast mit Nothwendigkeit einen solchen Heilungsvorgang fur manche Fälle supponiren müssen.

Ferner findet man so häufig bei Sectionen auf dem Peritoneum and der Pleura neben evidenten Resten abgelaufener Entzündungen (Verdickungen, Trübungen, bindegewebige Adhaerenzen, Neomembranen etc.) kleine, den Miliartuberkeln äusserst ähnliche Knötchen. Untersucht man dieselben aber mikroskopisch, so findet man nicht Tuberkelelemente, sondern die Knötchen bestehen aus derbem, fibrösem Gewebe. Man denkt, wenn man dies sieht, unwillkürlich an eine hier stattgefundene Ausheilung der tuberculösen Entzündung.

Ich will gleich hier schon erwähnen, dass ich auch bei der Tuberculose der Iris in manchen Knötchen diese centralen Kernconglomerate getroffen habe, wenn auch nicht häufig.

Den ersten Fall von Conjunctivitis tuberculosa sah ich vor 4 Jahren bei Prof. Graefe in Halle. Die Affection war so eigenartig und fremd, dass Prof. Graefe ein Stück der gewucherten Schleimhaut des oberen Lides excidirte und mir zur Untersuchung übergab, wobei es sich herausstellte, dass eine hochgradige Infiltration der Conjunctiva mit Tuberkeln vorliege. - Die Krankengeschichte ist folgende:

1) Christian B., 32 Jahre alt. Das reehte Auge thränt seit 2 Jahren, das linke seit $1 \frac{1}{2}$ Jahren. Erst seit $1 / 2 \mathrm{Jahr}$ bemerkte Patient die Anschwellung des rechten oberen Lides. 
Seit 7. Februar 1876 ist Patient in Behandlung von Prof. Graefe.

Status. Etwas schwächliches, blasses Individunm, das sonst gesund ist, Lungen frei. Die Umgebung des rechten Auges geröthet, das obere Lid stark verdickt, hängt über das untere herab. Das Auge kann wegen der Schwere des oberen Lides nicht geôfnet werden. Die ganze Conjunctiva tarsi sup. dick mit granulationsartigen Wucherungen bedeckt, deren Farbe lebhaft roth. Die Conjunctiva bulbi ist ganz frei, ihre Gefässe etwas stärker gefüllt, Pericorneal-Injection, Reibungspannus ther die ganze Cornea sich ausdehnend, so dass die ophthalmoskopische Untersuchung unmöglich; man bekommt bloss rothes Licht herans. - Linkes Ange bis auf den Thränensack normal, dieser dagegen stark ausgedehnt, bildet eine fast haselnussgrosse Geschwulst. Beim Incidiren zeigt es sich, dass der Thränensack mit ähnlichen, granulationsartigen Wucherungen ansgefüllt ist, wie sie rechts die obere Lidconjunctiva bedecken. Die Thränensack-Wucherungen werden ron Prof. Graefe ausgekratzt, worauf or noch Cauterisation folgen liess.

Die folgenden Fälle von Conjunctivitis tuberculosa verdanke ich der Freundlichkeit von Herrn Prof. Horner und entnehme ich die jeweiligen Krankengeschichten seinen Protocollen.

2) Agathe M., $18 \mathrm{Jahr}$ alt, kam zuerst am 22 . Mai 1874 zur Untersuchung. Das rech te Auge ist seit 4 Jahren krank. Beide Lider ganz verdickt, die Innenfläche des oberen mit kolben- und zottenförmigen Auswüchsen besetzt. Die Innenfläche des unteren Lides ist mehr mit abgeflachten Wucherungen bedeckt, die Aehnlichkeit mit Trachomkörnern haben. Eine fünfmonatliche Behandlung (Scarification der Wucherungen, Excision, Cauterisation etc.) bringt die Affection nur wenig zurück. Sie warde am 26. October mit Cuprum - Salbe entlassen. Schon im Januar des folgenden Jahres (1875) erscheint Patientin wieder. Die Granulationen sind wieder sehr gross, sowohl am oberen als am unteren Lid des rechten Auges. Es wird jetzt ein Theil derselben, sowobl oben als unten mit der Seheere abgetragen. - Ende dieses Jahres trat Patientin abermals in Behandlung, da die Granulationen wieder 
nachgewachsen waren. Sie wurde mit der Ordination: Leberthrancur entlassen (11. December). Ein Jahr später, den 20. November 1876 zeigt sich Patientin, die seither regelmässig Leberthran getrunken, wieder. Der Zustand der Conjunctiva des oberen lides ist fast wieder derselbe, wie früher. Die Granulationen auf der Conjunctiva des unteren Lides dagegen haben abgenommen. Am 23. November 1876 werden nun die Wucherungen auf der Conjunctiva des oberen Lides sehr energisch exstirpirt. - Am 12. Juli 1878 erfährt man durch Bericht von der (entfernt von hier lebenden) Patientin, dass der Zustand des Auges jetzt ein sehr befriedigender sei.

Die im Laufe der Behandlung excidirten versehiedenen Stücke differiren im mikroskopischen Befund etwas. In den älteren Stücken finden sich nebst starken, papillenähnlichen Granulationswucherungen, aus gewöhnlichem klein- und rundzelligen Granulationsgewebe bestehend, deutliche und unzweifelhafte Tuberkel in ziemlicher Menge, aber nicht in den papillen- und zottenăhnlichen Wucherungen, sondern ganz in der Tiefe, zunächst dem Tarsus. Hier und da sieht man dieselben schon in kăsigem Zerfall begriffen. Reticulum und epitheloide Zellen sind in typischer Anordnung in den Tuberkeln leicht nachweisbar. Riesenzellen finden sich in vielen Knötchen, doch nicht in allen. In den jüngeren Stücken tritt die Tuberkelbildung mehr zurück vor dem Granulationsgewebe, das sehr stark vascularisirt ist. Das Ueberwipgen des Granulationsgewebes rührt hier wohl von der örtlichon, reizenden Behandlung her. Die Tubrkel zeigen in diesen Stücken grosse Tendenz zu Necrose und Verkäsung.

3) Lisette H., 33 Jahre alt, wurde im Jahre 1875 längere Zeit hindurch wegen Dacryocysto-blenorrhoe links behandelt und zwar vermittelst Spaltung des oberen Thränenkanälchens und Sondirung. Im Januar 1877 präsentirte sich Patientin, die seither nicht in Behandlung gewesen, wieder, diesmal aber wegen der Beschwerden (Druck im Auge, Secretion), welche durch Granulationsmassen auf der Innenflache des oberen Lides des linken Auges verursacht wurden. Dieselben sahen ganz analog denen in den beiden vorigen Fällen aus. Sie überzogen jedoch nicht die Fläche der ganzen Conjunetiva, sondern standen, sogenannten Granulationsknötchen ähnlich, mehr isolirt, indem sie sich $4-5 \mathrm{Mm}$. über das 
Niveau der Schleimhaut erhoben. Die Wucherungen werden mit der Scheere abgetragen. Im März, also zwei Monate nachber, waren die Granulationen schon wieder nachgewachsen. Dieselben wurden wieder entfernt und die Stellen mit Arg. nitr. cauterisirt. Im November desselben Jahres wurde aber schon wieder eine Abtragung der Wucherungen nöthig, die jetzt mehr auf der oberen Uebergangsfalte, nahe der ausseren Commissur sassen. Folgt Cauterisation. Dieselbe Procedur wurde im Jahre 1878 schon im Januar wieder nothwendig. Am 13. April ist die Stelle, wo die Granulationen gesessen hatten, gut vernarbt, nur wenige kleine Granula sind noch zu sehen. In der Uebergangsfalte des unteren Lides zeigen sich einige Follikel. Abtragung der kleinen Wucherungen. Schon am 16. Juli d. J. finden sich wieder neue, prominirende Elemente, die wohl bald wieder eine Entfernung nothwendig machen werden. Seit jener ersten Sondenbehandlung war eine weitere Erkrankung des Thränensackes nicht mehr zu Tage getreten und in dieser Richtung auch keine Behandlung nothwendig gewesen.

Wăhrend in diesem Falle die Wucherungen auf der Schleimhaut des oberen Lides nicht so ausgebreitet sind, wie sonst und mehr bloss die äussere Halffte der Conjunctiva und Uebergangsfalte beschlagen, zeichnet sich das Leiden hior durch auffallendè Hartnäckigkeit ans. $O b$ der tuberculöse Process auf der Sehieimhaut des Thränensackes begonnen hat und auf die Conjunctiva übergegangen ist, oder ob die Affection der Conjunctiva secundăr durch eine vielleicht gewöhnliche Dacryocystitis angefacht wurde, ist nicht zu entscheiden. Eine länger dauernde Schwellung der Thränensackgegend war nicht vorhanden. Das aber ist sicher, dass anatomisch die Wucherungen, welche zu verschiedenen Zeiten excidirt wurden, den in den anderen Fallen von Conjunctival - Tuberculose excidirten glichen, d. h. jmmer sehr zahlreiche Tuberkelknötchen enthielten.

Im Uebrigen war die Pationtin gesuna und ron robustem Ansseben.

4) Anna R., 22 Jahre alt, kam im März 1877 in Behandlung ron Prof. Horner. Sie zeigte sehr starke Drüsenschwellung vor und unter dem linken Ohr. Das linke obere Lid ist ungemein vergrössert und verdickt und zeigt schon äusserlich ausgedehnte Gefässe. Die Innenfläche des Lides ist 
mit massenhaften, papillären Wucherungen überzogen, die auf dick infiltrirtem Grund sitzen. Die Wacherungen sind an der oberen Uebergangsfalte, nahe der äusseren Commissur zerfallen. Diese Zerfallstellen zeigen speckigen, hart infiltrirten Grund und grauliche Farbe. Die Conjunctiva des unteren Lides ist diffus geschwellt und injicirt. Conjunctiva bulbi frei. Patientin, die sich keiner geregelten Behandlung unterziehen konnte, erschien ein Jahr spăter, Mărz 1878, wieder, da der Zustand des Auges seit einigen Wochen sich noch verschlimmert hatte. Der Befund war ähnlich dem vom vorigen Jahre, nur waren die Granulationen noch mãchtiger. Doch zeigt die Conjunctiva des unteren Lides auch jetzt keine Granulationen, sonder nur sammetartige Oberfläche. Die Drüsen unter dem linken $\mathrm{Ohr}$ und Unterkiefer sehr stark geschwellt, ebenso die Cervicaldrüsen. Rechts dagegen lassen sich nirgends, weder am Unterkiefer, noch am Hals vergrösserte Drüsen nachweisen. Am 23. April sind die Drüsensehwellungen noch bedeutender. Es wird jetzt der grösste Theil der gewucherten Mucosa abgetragen. Die Heilung erfolgt rasch, die Wirkung der Operation ist gut, so dass das Auge wieder geöffnet werdẽ̃ kann. Die Patientin wird mit der Weisung entlassen, Kempten-Sulzbrunner Wasser zu trinken. Am 27. Mai ist eine deutliche Abnahme der Druisenschwellungen am Halse zu constatiren, auch ist das Lid noch mehr verkleinert, die Wacherungen auf der Conjunctiva haben nicht recidivirt. Es wird Fortgebrauch des Jod-Wassers empfohlen.

Die mikroskopische Untersuchung der excidirten Schleimhantpartie ergiebt ein den übrigen Fällen ganz analoges Bild. Die Tuberkel, mit und ohne Riesenzellen, aber von ganz typischem Bau, finden sich massenhaft. Daneben auch viel stark vascularisirtes, kleinzelliges Granulationsgewebe.

5) Anna B., 14 Jahre alt. Ende Juli 1877 stellt sich diese Patientin vor mit folgendem Befund an dem seit mehreron Wochen erkrankten rechten Auge. In der Vebergangsfalte sowohl des oberen, als des unteren Lides mächtige Granulationswucherungen von grau-rother Färbung. Diese Wucherungen beschrănken sich ganz allein auf das Gebiet der Uebergangsfalte, während sowohl oben als unten die Conjunctiva auf dem Bereich des Tarsus bloss sammetartige, papilläre Schwellung zeigt. Nebst sehr starker Gefässentwickelung 
starke eitrige Secretion. Beiderseits alte Maculae corneae, links Follicularcatarrh. Drüsen vor dem $\mathrm{Ohr}$ nieht geschwellt, dagegen die Tonsillen. Ferner: reichliche Granula auf der hinteren Pharynxwand, heisere Stimme. - Abtragung der speckigen, etwas durchscheinenden Massen, welche wie aus einzelnen sehr grossen Follikeln zusammengesetzt erscheinen, von der Conjunctiva des unteren Lides. Die Behandlung wird nun bis zum October mit Abtragung der Wucherungen, Cauterisation, gelber Präcipitalsalbe weiter geführt. Am 13. October ist der Zustand des Auges befriedigend, die Granulationen sind weg. Der Pationtin wird bei der Entlassung Leberthrancur während des Winters empfohlen.

Der mikroskopische Befund der excidirten Stincke ist folgender: oberflächlich unter dem Epithel findet sich Granulationsgewebe mit sehr zahlreichen Gefässen und vielen Blutextravasaten. In dem Granulationsgewebe sind ganz kleine Tuberkelknötchen in mässiger Zahl eingebettet. In der Tiefe, ganz nahe dem Tarsus, fallt nebst zerstreuten, kleineren Tuberkeln namentlich ein fast $0,5 \mathrm{Mm}$. grosser Knoten, aus 4 bis 5 typischen, kleinen Tuberkelknötchen zusammengesetzt, auf, der von einem dichten Ring von Rundzellen umgeben ist. An den Präparaten dieses Falles sieht man häufig kleine Heerde von Rundzellen, die noch nicht den Charakter von Tuberkeln haben, nahe an Gefässen liegen. Ferner trifft man viele strotzend gefüllte Lymphgefässe. Grosse Riesenzellen sind seltener, doch fehlen sie, meist im Centrum von Tuberkelknötchen liegend, nicht. Ganz vereinzelt sieht man auch da und dort einen jener oben erwähnten dichten Haufen kleiner Kerne das Centrum des Tuberkels einnebmen. Von Follikelbildung innerhalb der Granulationsmassen ist nichts zu sehen. Die makroskopisch wie grosse Follikel aussehenden Gebilde sind Granulationen mit oder ohne Tuberkelinhalt.

6) Caroline K., 17 Jahre alt. Diese Patientin präsentirte sich zum ersten Mal im Januar 1878 mit starker erysipelartiger Schwellung der Lider des linken Auges. Auf der Conjunctiva sowohl des oberen, als des unteren Lides finden sich hahnenkammförmige, mehr isolirt stehende Wucherungen von grau- bis gelblich-rother Farbe. Deber dem Thränensack eine starke Schwellung, die (wie auch gleich diagnosticirt wurde und wie es sich dann bei der Operation zeigte) durch 
Wucherungen glejeher Art auf der Schleimhant des Thränensackes verursacht wurde. Zahlreiche, stark geschwellte Lymphdrüsen finden sich vor dem linken Ohr und unter dem linken Unterkiefer. - Rechts ist die Conjunctiva ganz normal. Es lassen sich auf dieser Seite absolut keine Drüsenschwellungen nachweisen. Nebst Gebrauch von Jodkali innerlich und krăftiger Diät wird jetzt zur Abtragung der Wucherungen, Eroffinung und Ausräumung des Thränensackes geschritten. Eine einmonatliche Behandlung vermindert wohl die Granulationen, beseitigt sie und namentlich die diffuse Schwellnng der Conjunctiva aber nicht ganz und verkleinerte auch die geschwellten Drüsen nicht. Die Patientin soll zu Hause das Jodkali weiter gebrauchen.

Auch hier mikroskopisch zahlreiche Tuberkelknötchen, analog den oben geschilderten Befunden. Riesenzellen finden sich nur in etwa der Hälfte der Knötchen. Die übrigen entbehren derselben oder zeigen oft im Centrum statt der Riesenzellen einen gedrăngten Kernhaufen. Daneben aber trifft man auch ziemlich viele Tuberkel, die central in beginnender Verkäsung begriffen sind.

Dies ist in Kurzem der klinische und anatomische Befund in sechs Fällen von Conjunctivitis tuberculosa. Einige diagnostische Bemerkungen darf ich nicht unterlassen noch beizufügen. Es erhob sich in mehr als einem der Fälle die Frage: haben wir es nicht etwa mit Lupus zu thun? Allerdings ist bis jetzt bloss ein Fall von primärem Lupus der Conjunctiva bekannt ge. macht worden und zwar von Arlt*), d. h. es ging in diesem Fall die Lupuseruption auf der Conjunctiva derjenigen auf der Wange und dem Nasenflügel viele Wochen vorher. Einen ähnlichen Fall von primärem Lupus conjunctivae sah ich im Jahre 1875 auf der v. Arlt'schen Klinik. Hier war die Conjunetiva bulbi Sitz der damals von Arlt als Lupus bezeichneten Affec-

*) Zehender's klin. Monatsbl. 1864, pag. 330. 
tion. Auch in diesem Fall fehlte noch jede Erkrankung der Haut des Gesichtes. In den oben geschilderten sechs Fällen lässt sich, da sie alle längere Zeit unter Beobachtung standen, Lupus mit Sicherheit ausschliessen, abgesehen davon, dass der Lupus der Conjunctiva sich durch die Tendenz charakterisirt, uber den intermarginalen Theil hinüber auf die Cutis zu greifen*).

Dieses Ueberschreiten der Schleimhautgrenzen fehlt in unseren Fällen absolut, ja die Affection nähert sich nie, auch bei sehr langem Bestehen etwa mit Vorliebe dem Lidrand, bleibt vielmehr oft die längste Zeit auf die Uebergangsfalte beschränkt (vergl. Fall 3 und 5). Dann darf erwähnt werden, dass in unserer Gegend überhaupt der Lupus gar nicht băufig ist. Ferner, und dies ist ein gewichtiger Punkt, sah man auch nach sehr langer Dauer der Affection in unseren als Conjunctivitis tuberculosa bezeichneten Fällen niemals spontan grössere, lupusähnliche Vernarbungen eintreten. Aus diesen Gründen kann eine Verwechselung mit Lupus in den geschilderten Krankheitsbildern bestimmt ausgeschlossen werden. Dagegen gebe ich sehr gern zu, dass mikroskopisch der Unterschied zwischen den Tuberkelinfiltraten in der Conjunctiva und dem Gewebe einer von Lupus hypertrophicus befallenen Hautpartie kein sehr grosser ist. Auch beim Lupus haben wir häufig grosse, gut ausgebildete Riesenzellen inmitten rundlicher Knötchen, deren Zellen den epitheloiden Zellen des Tuberkels sehr ähnlich sind. Verschafft man sich aber Uebersichts" bilder dadurch, dass man grössere Schnitte vom Lupus (bypertrophicus) mit schwachen Vergrösserungen studirt, so macht sich der Unterschied zwischen der Anordnung dieser Knötcheninfiltration und dem typischen Tuberkel-

*) v. Wecker. Graefe u. Sämisch's Handb., Bd. 4, pag. 161. 
knötchen sehr wohl bemerkbar. Beim Lupus (hypertrophicus) haben wir eine viel stärkere Confluenz der knötchenförmig in das Cutisgewebe eingelagerten Neubildung. Es ist die Zone von kleinen Rundzellen, welche den legitimen Tuberkel gewöhnlich umschliesst, weniger ausgeprägt. Die Lupusknötchen gehen ohne solche kleinzellige Grenzzonen unmittelbar in einander tuber, bilden so unregelmãssige, landkartenförmige Figuren, deren Zwischenräume durch zellenreiche Züge von Cutisgewebe ausgefüllt werden,

Mit granulöser Conjunctivitis oder Trachom ist eine Verwechselung, wie sich schon aus der ganzen obigen Schilderung ergiebt, kaum möglich. Eine etwelche Aehnlichkeit dagegen hat die tuberculöse Affection hier und da (z. B. im Fall 1, 2 und 4) mit dem Zustande, in welchem sich eine total vernachlässigte Blennorrhoe (gonorrhoica und neonatorum) etwa in der sechsten Woche befindet. Nur baben die zottigen, üppig wuchernden Granulationen bei sich selbst überlassener Blenorrhoe ein viel rötheres, succulenteres Aussehen, als die tuberculösen Wucherungen, die jenen gegenüber eher grauroth, etwas speckig, leicht durchscheinend genannt werden müssen.

Deber die Prognose der Conjunctivitis tuberculosa kann ich vorläufig nichts Bestimmtes aussagen. Aber der Umstand, dass wir es mit einer Tuberculose zu thun haben, muss uns in der Beurtheilung der Dignität des Processes offenbar eher dahin führen, denselben als einen dubiösen zu erklären. Es ist die sogenannte locale oder sagen wir lieber chronische Tuberculose jedenfalls nicht unter die harmlosen Affectionen zu stellen, wenn ich auch die Ansicht Hüter's*), dass da,

*) Bericht der 50. Versammlung deutscher Naturforscher und Aerzte in München, pag. 281. 
wo Localtuberculose existirt, das Leben sich in grösster Gefahr befinde, als nicht genügend bewiesen ansehe. Der von Marchand*) erwähnte Fall zeigt allerdings in prägnanter Weise, wie von einem tuberculös erkrankten Gelenk aus sich die Tuberculose nach und nach in deletärer Weise über den ganzen Organismus ausbreiten kann. Sollten sich ähnliche Beobachtungen häufen, so könnte damit auch die Prognose der uns hier beschäftigenden Affection präciser formulirt werden. - Dass das Conjunctivalleiden sehr hartnäckig und lästig sein kann, sahen wir aus einigen der angeführten Krankengeschichten (z. B. Fall 3). Auffallend ist die Trägheit, mit der die Tuberkelwucherungen um sich greifen. Es kann der Process z. B. die längste Zeit anf der Conjunctiva des oberen Lides localisirt bleiben. - Da die Tendenz zur Vernarbung sehr gering ist, leidet die Stellung der Lider nicht.

Die Behandlung ist in erster Linie eine allgemeine in dem Sinne, wie wir sie gegen Scrophulose einzuschlagen pflegen. In zweiter Linie sind Abtragungen der Wucherungen resp. umfangreiche Excisionen der entarteten Schleimhaut indicirt, aus zwei Gründen. Erstens wird dadurch der Zustand erträglicher gemacht, der Patient erbält unter Umständen die Gebrauchsfähigkeit des Auges wieder (durch Entlastung des oberen Lides). Zweitens ist die Entfernung der Tuberkelmassen, bevor sie verkäsen, zerfallen und vielleicht verschleppt werden, geboten, ähnlich, wie dies bei der Auskratzung einer fungös wuchernden Synovialis einer der leitenden Gesichtspunkte ist. Es werden auch diese Abtragungen und Excisionen, eventuell unter-

*) Bericht der 50. Versammlung deutscher Naturforscher und Aerzte in München, pag. 282. 
stätzt durch Cauterisationen, sehr gut ertragen, ohne dass unangenehme Vernarbungen eintreten.

\section{Die Iritis und Iridocyclitis tuberculosa (Granuloma Iridis).}

Typische Miliartuberkel wurden im Irisgewebe zum ersten Mal von Gradenigo*) anatomisch nachgewiesen. Dann folgt die Mittheilung von Perls**). Dafür, dass die Iris auch Sitz einer sogenannten localen Tuberculose sein könne, wurde von Köster***) der erste Nachweis erbracht, indem er in einem Irisgranulom, das die Cornea perforirt hatte, Tuberkelkuötchen fand. Eine Anzahl früherer anatomischer Untersuchungen von sogenannten Granulomen der Iris (durch Virchowt), Billrotht), Rosowtt), Berthold tht), Hirschberg und Steinheim*) constatirten als Hauptbestandtheile des Granuloms dagegen bloss klein- und vielzelliges Bindegewebe oder schleimhaltiges Granulationsgewebe. Es ist aber schon auffallend, dass die meisten dieser Untersucher Myeloplaxen und Riesenzellen in dem Gewebe vorfanden. In einem von Saltini**+) beobachteten Falle von Tumor auf der Iris, wo nach Durchbruch der Geschwulst nach aussen von Manfredi***i) die anatomische Untersuchung vorgenommen wurde, erklärte letzterer die Neu-

*) Annal. d'ocul., Bd. 64, pag. 174.

**) Graefe's Archiv f. Ophthalm. Bd. 19, 1., pag. 221.

**) Centralbl. f. d. med. Wissenschaften. 1873.

t) Archiv f. Ophth., Bd, 7, 2, pag. 37.

t†) Archiv f. Ophth., Bd. 12, 2, pag. 231.

$+t f)$ Archiv f. Ophth., Bd. 17, 1, pag. 17.

*) Archiv f. Augen- u. Ohrenheilkunde. 1. Bd., pag. 144.

*) Annali di Ottalm. IV., pag. 127-131.

${ }^{* *}+$ ) Annali di Ottalm. IV., pag. 265-314. 
bildung auf das bestimmteste für eine tuberculöse. Dagegen spricht sich Sattler*) bei der anatomischen Beschreibung eines Granuloma Iridis nicht bestimmt darüber aus, ob wirklich Tuberkel sich in der Neubildung fanden. Der Schilderung nach möchte man dies annehmen.

Um dieselbe Zeit war von Prof. Graefe in Halle ein Bulbus enucleirt worden mit Wucherungen auf der Iris, in welchen von Prof. Steudener zahlreiche typische Tuberkel gefunden wurden. Ich untersuchte im Jahre 1876 jenen Bulbus ebenfalls mit ubereinstimmendem Resultat and die Details dieses noch nicht publicirten Befundes folgen unten sub $\mathrm{Nr}, 16$. Jüngst hat auch Weiss in einem seiner drei Fälle von Tuberculose des Auges die Iris von einer Tuberkeleruption betroffen gefunden. Auch in diesem Fall war vor der Enucleation die Diagnose auf Granulom der Iris gestellt worden.

Ich hatte Gelegenheit, in 4 Fällen von sogenanntem Granulom der Iris und des.Corpus ciliare eine genaue anatomische Uutersuchung vorzunehmen. Jedesmal bildeten Tuberkelknötchen, eingelagert in das infiltrirte Stroma der Iris und des Corpus ciliare, die Hauptnasse der Geschwulst. Dds Irisgranulom zeigt fast noch deutlicher als die Tuberculose der Conjunctiva, dass das Wesentliche des Processes in der Entwickelung gedrängt beisammen stehender, typischer Miliartuberkel liegt.

Der Name "Granulom" hat, wie mïr scheint, in die richtige Auffassung dieser Krankheitsform einige Verwirrung gebracht. Die Bezeichnung "tuberculöse Iritis", die man in älteren Autoren da und dort für diese Affection findet, war entschieden besser. Die Schilderung, welche z. B. schon Jakob in seinem, Treatise on the inflammations of the eyeball" (Dublin 1849) von der, wie

*) Becker's Atlas. II. Lieferung, pag. 36 . 
er sie nennt, "scrophulösen oder tuberculösen Iritis", pag. 163 u. ff. giebt, ist nichts anderes, als eine ganz vorzügliche Schilderung des Granuloms der Iris.

Er sagt: „Die Iris ist in dieser, wie in allen anderen Entzündungen des Augapfels, hauptsächlich afficirt und die Veränderung ihrer Färbung ebenso wie die Contraction und Verlöthung der Pupille sind eben so hervorstechend, wie bei den anderen Formen der Iritis. Indessen sieht man, wie ich glaube, nur bei der scrophu* lösen Iritis sich Ablagerungen (Deposits) bilden, ähnlich denen, welche man bei syphilitischer Iritis trifft und welche man gewöhnlich als plastische Lymphe auffasst. Aber die Ablagerungen, welche sich bei der scrophulösen Iritis bilden, sind nicht von derselben Natur, wie bei der Iritis syphilitica. Sie bestehen vielmehr aus wirklicher tuberculöser Masse und anstatt resorbirt zu werden, wie bei der syphilitischen Iritis, nehmen sie an Grösse beständig zu und brechen endlich, wie ein $\mathrm{Ab}$ scess nach aussen oder zuweilen, aber sehr selten, in die vordere Kammer auf. Ich betrachte diese tuberculöse Masse als den unzweideutigsten und am meisten charakteristischen Beweis für die scrophulöse Natur der Krankheit und ich halte die anderen, oben erwähnten Structurveränderungen nur um so mehr für Beweise der mit der ganzen Constitution in Beziehung stehenden Natur (der Affection). Die tuberculöse Ablagerung (Deposition), von der wir hier reden, findet sich gewöhnlich auf den peripheren Theilen der Iris, nahe dem Ligamentum ciliare und folglich hinter dem Cornealrand liegend. Sie besteht im Anfang aus einer unregelmässigen, gelblichen Masse mit darauf verlaufenden Gefässen, ähnlich den Ablagerungen bei Iritis syphilitica. Aber sie (die Ablagerung) wächst zusehends und breitet sich über die Cornealgrenze aus unter die Sclera, welche davor zurückweicht und der Wucherung gestattet, unter 
der Conjunctiva eine gelbliche Hervorragung zu bilden. Diese Masse fährt fort $\mathrm{zu}$ wachsen und sieht fast aus wie ein Abscess; sie ist in einigen Füllen so prominent und unregelmässig, so reich versehen mit weiten, geschlängelten Gefässen und die rings herum durch die verdünnte Sclera durchschimmernde Schwärze der Chorioidea giebt ihr ein solches Aussehen, dass man sie hier und da für einen malignen Tumor gehalten hat, so sehr ähnelt sie dann einem Fungus haematodes" u. s. w. - Wenn wir auch heut zu Tage unter tuberculösen Massen oder Ablagerungen etwas anderes verstehen als Jakob damit bezeichnete, so hat es mit der "tuberculösen Iritis" trotzdem seine völlige Richtigkeit und ich möchte die Jakob'sche Schilderung ohne Weiteres als zutreffend für die Affection hinstellen, welche wir jetzt Granulom der Iris nennen oder welche ich als wirkliche tuberculöse Iritis bezeichnen möchte.

Dass die tuberculöse Natur des Granuloms nicht schon von früheren Beobachtern als Regel constatirt wurde, dürfte zum Theil darauf beruhen, dass manchmal bloss kleine Stückchen der nach aussen durchgebrochenen Geschwulstmasse untersucht wurden (so in dem ersten v. Graefe'schen Fall, untersucht von Virchow und Billroth). Abgesehen davon, dass die manchmal disseminirt im stark infiltrirten Irisstroma stehenden Tuberkelknötchen natürlich auf grösseren, übersichtlichen Schnitten klarer hervortreten (dieser Punkt ist zwar bei geübten Beobachtern nicht so wichtig), ist es nicht gleichgültig, ob man die intraoculare Wucherung oder aber die extrabulbären Massen derselben untersucht, indem letztere mehr junges Bindegewebe und Granulationsgewebe enthalten, d. $h$. es überwiegt in diesen letzteren Partien, wie in gewissen Fällen der Conjunctivitis tuberculosa, in Folge der Reizung durch den Lidschlag und vielleicht der Thränenfliussigkeit, das 
Granulationsgewebe so, dass die wenigen Tuberkelknötchen davon ganz eingehüllt werden und darin fast verschwinden. Anders dagegen gestaltet sich das Aussehen der Neubildung innerhalb der vorderen Kammer. Da kann man an grösseren Schnitten, die ein übersichtlicheres topographisches Studium gestatten eine geradezu typische Anordnung der die Geschwulstmassen constituirenden Elemente mit Leichtigkeit wahrnehmen. Die weiter unten bei der Schilderung der einzelnen Fälle folgenden anatomischen Befunde werden dies beweisen.

Dem eben citirten klinischen Bilde, das Jakob von der tuberculösen Iritis entwirft, muss ich noch einiges beifügen. Indem ich zu den vier anatomisch von mir untersuchten Fällen noch alle übrigen von Prof. Horner klinisch beobachteten Fälle von Granulom beiziehe, deren Krankengeschichten er mir freundlichst zur Verfügung stellte, hoffe ich die klinisch wichtigen Punkte der Affection noch pıäciser feststellen zu können. Es belauft sich die Zahl der beobachteten Fälle so auf $\mathrm{z}$ wölf, aus welchem Material, zusammen mit dem, was sich in der Literatur bereits vorfindet, ich folgende Schlüsse ziehe:

Man kann die Iritis tuberculosa bezüglich des klinischen Verlaufes in 2 Gruppen theilen:

1) in eine kleinere Gruppe, wo die auf der Iris autschiessenden Knötchen, nachdem sie längere Zeit bestanden, sich vermehrt und zu vielen Beschwerden Veranlassung gegeben haben, nach und nach, ohne dass Durchbruch nach aussen erfolgt, wieder verschwinden, wobei das Auge entweder in ordentlichem Zustand und functionsfähig verbleibt oder aber an schleichender Chorioiditis etc. nach und nach $\mathrm{zu}$ Grunde geht.

2) eine grössere Gruppe, die die Mehrzahl der Fälle umfasst. Es brechen hier die Tuberkelwucherungen nach aussen durch und der Bulbus wird phthisisch. 
Was die erste Gruppe betrifft, so ist klar, dass dort nur Fälle untergebracht werden dürfen, in denen sich Syphilis mit Sicherheit ausschliessen lässt. Dies festgestellt, beobachtet man an Fällen dieser Kategorie folgendes: das ganze Krankheitsbild wird, besonders im Anfang, beherrscht durch die Symptome der Iritis serosa. Die Affection zeigt meist einen ungemein langwierigen Verlauf. Anatomische Untersuchungen der hier anftretenden, meist bloss disseminirt stehenden Knötchen liegen bis jetzt nicht vor. Das makroskopische Aussehen aber stimmt vollständig mit dem Anfangsstadium der Iritis tuberculosa überein und es scheint mir der Schluss nicht zu gewagt, dass wir es auch hier mit richtigen miliaren Tuberkeln zu thun haben. Sind aber die Wucherungen auf der Iris wirklich tuberculöser Natur, so böte folgerichtig diese, allerdings ziemlich seltene Affection die Möglichkeit, eine Ausheilung ron Tuberkelknötchen direct nachzuweisen. Diese Möglichkeit widerspricht allerdings sehr den Anschaungen, die wir gewöhnlich von der Heilungstendenz des Tuberkels haben. Es hat jedoch noch Niemand beweisen können, dass eine noch auf beschränktem Rayon localisirte tuberculöse Entzündung nicht auszuheilen im Stande sei, dass eine einmal ausgebrochene Tuberkelentwickelung in einem Organismus unter allen Umständen, gleich einem malignen Tumor nur durch den Tod sistirt werde. Und gesetzt auch, dies wäre wirklich der Fall, so dürfen wir doch so lange diese hier in Frage stehende Affection als tuberculöse bezeichnen, als nicht nachgewiesen ist, dass die davon betroffenen Individuen auch für alle spätere Zeit von Tuberculose verschont bleiben. Ich möchte hier ferner auf die oben pag. 178 gemachten Bemerkungen verweisen und wiederholen, dass wir in den dort beschriebenen centralen Kernhaufen (s. Fig. 5), die auch in den Tuberkeln der Iris hier und da zu treffen sind, 
vielleicht das anatomische Substrat einer solchen Ausheilung des Tuberkels erblicken dürfen. - Es hat in vielen Fällen von Granulom wohl das zur Zeit gute Aussehen und Wohlbefinden des Patienten den Ausschlag in der Richtung gegeben, die Neubildung als nicht tuberculös, als unschuldige Granulationsbildung, als "Lymphom" aufzufassen.

Die unten folgenden Krankengeschichten enthalten 5 Fälle, die ich dieser ersten Gruppe von tuberculöser Iritis subsummiren möchte. Auch die zwei Beobachtungen von Gradenigo und von Perls gehören offenbar in diese erste Kategorie. Sie zeigen einen etwas abweichenden Verlauf und die in den übrigen Fällen so stark hervortretenden Symptome der Iritis serosa dominiren hier weniger. Sie endeten beide nach einiger Zeit mit Tod, herbeigeführt durch acute Miliartuberculose. Gradenigo machte schon intra vitam die Diagnose tuberculöse Iritis und die mikroskopische Untersuchung bestätigte die tuberculöse Natur der Knötchen. Im Fall von Jacobson, untersucht von Perls, ähnelte die Neubildung auf der Iris sehr einem Gumma, wofür auch die Anamnese sprach. Der hier ziemlich grosse Knoten zeigte bei der mikroskopischen Untersuchung, namentlich in der hinteren, den Processus ciliares eingelagerten Partie zahlreiche typische Tuberkelknötchen. Man könnte wohl in der Literatur noch eine Anzahl Fälle finden, die klinisch das Bild der nicht nach aussen wuchernden Tuberculose der Iris darbieten. So vielleicht die von Tyrrel „On diseases of the eye", vol. 1, pag. 310 geschilderte Beobachtung.

Die zweite Form der tuberculösen Iritis zeichnet sich dadurch aus, dass die Wucherungen bald schneller, bald langsamer an Volumen zunehmen und die vordere Kammer ganz oder grösstentheils ausfüllen. Der Process kommt gewöhnlich erst dadurch zur Ruhe, dass schliess- 
lich die Corneo - Scleralzone von der nach aussen vordringenden Neubildung durchbrochen wird, worauf zuerst Schrumpfung der nach aussen vorgedrungenen Massen, dann Phthisis bulbi eintritt. $\mathrm{Zu}$ bemerken ist, dass wie bei der ersten Gruppe, ja in noch höherem Grade hier auch das Corpus ciliare gewöhnlich mehr oder weniger in den Process einbezogen wird. Vom Ciliarmuskel aus dringt dann die Tuberkelbildung in die benachbarte Sclera vor. Diese wird von zahlreichen Knötchen durchsetzt, aufgefasert, worauf gewöhnlich ganz nahe der Cornealgrenze der Durchbruch erfolgt. In denjenigen Fällen, wo das Corpus eiliare in höherem Grade von der Tuberkeleruption betroffen ist, wird das Uebel höchst schmerzhaft. Es kann dies erst nach einiger Zeit eintreten, nachdem der Process Anfangs bloss auf die Iris localisirt war, oder aber es kann die Affection gleich von Anfang an Corpus ciliare und Iris zugleich ergreifen, wo dann die Erkrankung gleich mit den heftigsten Schmerzen beginnt. In sämmtlichen Fällen, die ich untersuchte, war die Choroidea frei von Tuberkelbildung.

Ganz ähnlich, wie bei der Conjunctivitis tuberculosa findet man auch bei der tuberculösen Iritis, sowohl der ersten als der zweiten Form, die Lymphdrüsen vor dem Ohr und am Unterkiefer derselben Seite oder auch beiderseits geschwellt, manchmal in hohem Grade. Es kann diese Drüsenschwellung entweder kurz vor oder zugleich mit der Erkrankung der Iris eintreten (siehe Krankengeschichte Nr. 7, 8, 10,11,12, 13, 15) oder aber erst im Verlauf des Processes, mehr. secundär (Fall III. von Weis s und Krankengeschichte Nr. 18).

Ob die teleangiectatische Form des Granuloms (die 2 Fälle von Mooren und Schelske) etwas mit der tuberculösen Iritis zu thun haben, lässt sich erst sagen, wenn einmal eine anatomische Untersuchung dieser 
seltenen Affection vorliegt. Ich möchte es aber bezweifeln. Es werden dies wohl eher cavernöse Tumoren sein. Das traumatische Granulom*), das eigentlich allein den Namen Granulom verdient, hat mit der tuberculösen Iritis nichts zu thun.

Diagnose. Die Tuberkelwucherungen im Irisgewebe ähneln am meisten den Gummata der Iris. Sie lassen sich aber von diesen hauptsächlich durch die Färbung unterscheiden. Das Gumma ist gewöhnlich mehr lebhaft gelbroth, der Tuberkel der Iris dagegen mehr grauroth und dabei etwas durchscheinend oder graugelb bis weisslichgelb und trüb (durch Verkäsung beringt). Wo, wie bei der zweiten Form, die Tuberkel gehäuft beisammen stehen und grössere höckerige Wucherungen bilden, ähnlich schlaffen Wundgranulationen, da ist die Diagnose gewöhnlich nicht schwer. Den Unterschied zwischen Gumma und Tuberculose macht ganz gut die Vergleichung der beiden diesbezüglichen Bilder in der "Iconographie ophthalmologique" von Sichel (1852-59) deutlich.

Fig. 5, Tafel XIII. giebt in ausgezeichneter Weise das Gumma Iridis wieder. Fig. 6 auf Tafel XXVI. dagegen ist wohl nichts anderes als eine tuberculöse Iritis, wenn auch Sichel die im unteren Theil der vorderen Kammer liegenden Massen als ein "Hypopyon d'une espèce particulière et très-rare" (observé sur un enfant lymphatique) bezeichnet. Der Farbenton dieser offenbar aus Knötchen zusammengesetzten Geschwulst giebt Sichel nur etwas zu stark bräunlich; wäre er mehr grauroth, so würde das Bild unserer Affection sehr gut entsprechen. Dass das Gumma gewöhnlich nahe dem

*) Knap p. Die intraocul. Geschwülste, pag. 221. pag. 459.

Alt. Archiv f. Augen- u. Ohrenheilk. 6. Band, II. Abth. 
Pupillarrand steht, das Granulom näher der Peripherie der Iris, ist von allen Beobachtern hervorgehoben worden. Doch giebt es, wenn auch selten, Gummata, die ganz peripher sitzen. Einen solchen Fall beobachteten wir vor Kurzem. Hier entschied nebst der Anamnese namentlich die mehr in's gelbroth gehende Färbung der aus zwei ziemlich grossen Knötchen bestehenden Geschwulst die Diagnose.

Ein Punkt fiel mir beim Durchgehen der Casuistik und der Betrachtung der eigenen Fälle auf, der bis jetzt nirgends erwähnt ist. In der Mehrzahl der Beobachtungen, die genan beschrieben sind und wo der Sitz der Wucherungen angegeben wird, ist die untere Hälfte der Iris von denselben eingenommen, namentlich im Anfang, wo sie noch klein sind. Der Grund hierfür ist mir nicht klar.

Es ist ferner bei der Diagnose auch der Allgemeinzustand des Patienten za berücksichtigen. Oft findet man als Begleiter der Augenaffection, wie schon erwähnt, Drüsenschwellungen, Infiltration der Lungenspitzen oder es stellt sich bei näherer Nachforschung heraus, dass Eltern oder Geschwister des Patienten an Phthisis resp. Tuberculose gestorben sind.

Prognose. Für das Auge ist die Prognose entschieden schlecht, namentlich bei der zweiten Form der Erkrankung. Da geht der Bulbus immer durch Phthisis zu Grunde, nachdem meist schon längere Zeit vorher das Sehvermögen bedeutend reducirt oder erloschen ist. Aber auch quo ad vitam ist die Prognose nicht ganz günstig. Die Zahl der Fälle, wo der Patient längere oder kürzere Zeit nach Beginn der Erkrankung des Auges an Tuberculose starb, ist verhältnissmässig gross. So starb im Fall von Sichel*) der Kranke (einjähriges

*) v. Hirschberg u. Steinheim im Archiv f. Augen- u. Ohrenheilkunde. Bd. I., pag. 146. 
Kind) an Phthisis mesaraica und Hydrocephalus acutus. In einem Fall, den Mackenzie ${ }^{*}$ ) erwähnt, starb die Patientin (19jähriges Mädchen) 3 Monate nach Beginn der Erkrankung des Auges. Die Section konnte zwar nicht gemacht werden. Mackenzie fügt aber bei: „Wahrscheinlich fanden sich im Gehirn noch mehr scrophulöse Tuberkel, ähnlich denen, die sich auf der Iris gezeigt hatten." Tödtlich endigten ferner die beiden Erkrankungen die Gradenigo und Perls erwähnen, und in einem Fall unserer Beobachtungen trat ebenfalls ziemlich bald der lethale Exitus ein, mit höchster Wahrscheinlichkeit in Folge von Meningitis tuberc. (Die Section konnte nicht gemacht werden. Krankengeschichte Nr. 18). Auch ein von Jakob pag. 164 kurz erwähnter Fall gehört wohl hierher und Jakob führt dabei als Aeusserung Mackenzie's an, dass mehrere Kranke dieser Art, die er gesehen, an chronischen Erkrankungen der Lungen gestorben seien. Diesen lethal endigenden Fällen steht allerdings eine grössere Zahl solcher gegenüber, wo mit dem Durchbruch der Wucherungen nach aussen and Phthisis bulbi die Sache abgethan war, die Patienten sich dann weiterhin wohl befanden, ja sogar an den Ablauf des Processes geradezu sich eine rasche Besserung des Allgemeinzustandes anschloss. Aber es bedürfte, um die gutartige Natur der Erkrankung festzustellen, einer noch längeren Beobachtungszeit, als in den bis jetzt publicirten Fällen angeführt ist. Vielleicht äusserte sich doch später die Tuberculose wieder irgendwo im Körper und es wäre im Interesse dieser Frage, die also die Möglichkeit der Ausheilung von $\mathrm{Tu}$. berculose betrifft, wichtig, bei den als geheilt entlassenen Patienten von Zeit zu Zeit nachzufragen und sich nach ihrem Befinden za erkundigen.

*) Traité prat, des maladies de loeil. Ed. IV., Bd. II., p. 265. 
Behandlung. Dieselbe ist in den meisten Făllen ziemlich machtlos. Nur da, wo die Knötchen keine grosse Tendenz haben, sich anzuhäufen und grössere rasch zunehmende Wucherungen zu bilden (Theil der Fälle erster Kategorie) ist es möglich, durch andauernde, namentlich diätetische Behandlung das Leiden im Auge zum Stillstand und Rückgang zu bringen. Frische Luft, Licht, kräftige Nahrung, Leberthran, Jodeisen, Soolbäder etc. sind die Waffen, mit denen man den ungewissen Kampf führen kann, abgesehen von den örtlichen Mitteln, wie Atropin und eventuell bei Drucksteigerungen, die dabei auch vorkommen, Eserin. Die Krankengeschichten Nr. 7-11 zeigen, auf welche Weise unter Umständen ein befriedigender Erfolg sich erzielen lässt. Wo die tuberculöse Neubildung nur auf einen Theil der Iris beschränkt ist, kann man versuchen, diesen sammt der Geschwulst zu excidiren. So operirte Rosas*) in einem Fall, wo der Tumor ein Dritttheil der Iris einnahm. Es trat kein Recidiv ein, die Sehschärfe blieb aber auf quantitative Wahrnehmung beschränkt. Prof. Horner operirte ebenfalls in 3 Fällen auf ähnliche Weise, aber ohne befriedigenden Erfolg. Dieser ist vollends nicht zu erzielen, wenn der Process das Corpus ciliare in Mitleidenschaft gezogen hat. In diesen Fällen und überhaupt da, wo die Wucherungen schon einigermassen beträchtlich sind und eine progressive Zunahme zeigen, ist die Enucleation das Richtigste. Erstens wird dadurch die Krankheit abgekürzt, der schmerzhafte Durchbruch der Bulbuscapsel in unmittelbarer Nähe des Corpus ciliare umgangen. Zweitens erspart man damit dem Patienten ein längeres Krankenlager, das seine häufig ohnedies schwache Constitution noch

*) Handbuch der theoretischen und prakt. Augenheilkunde. II. 617 . 
mehr herunterbringt. Drittens entfernt man schon-bestehende: oder jedenfalls sich bildende Käseheerde, die möglicherweise der Ausgangspunkt weiterer allgemeiner Miliartuberculose werden könnten.

\section{Krankengeschichten.}

1. Gruppe.

7) Bertha S., 20 Jahre alt, war bis zum 18. Lebensjahr gesund, litt dann $1 \mathrm{Jahr}$ lang an Menstruationsanomalien und wurde chlorotisch. Im Frühjahr 1867 schwollen die Drüsen der Parotisgegend an, es stellte sich Engigkeit ein, die die Patientin an jeder sehweren Arbeit verhinderte, Sie litt zudem häufig an Bronchialcatarrh. Im Sommer 1867 Abnahme der Sehschärfe beider Augen ohne jegliche Schmerzhaftigkeit derselben, aber von pericornealer Injection begleitet. Am 27. October 1867 stellte sich Patientin Prof. Horner vor.

Status: Beiderseits Iritis serosa. Links eine Synechie nach unten, zahlreiche Punkte auf der Descemet'schen Membran. Im Winkel zwischen Iris und Cornea ein stecknadelkopfgrosser, gelblich - weisser Tumor. Rechts Pupillarrand vollkommen frei, punktförmige Beschläge auf der Hinterfächo der Cornea. Beiderseits membranöse Glaskörperflocken. Warme Umschläge, Atropin, Eisen mit Chinin.

Am 27. Januar 1868 stellte sich Patientin wieder vor: Links drei grauröthliche Knötchen im unteren Theil der vorderen Kammer, das eine von der Grösse eines Schrotkornes, die beiden anderen etwas kleiner, eine Synechie nach unten. Rechts ein ganz kleines Kuötchen auf der Iris nach unten-innen, nahe dem peripheren Rand derselben. Drüsengeschwulst vor dem rechten Ohr. Ord. Eisen, Atropin, Tinct. Jodi auf die geschwellten Drüsen. Auf den Gebrauch des Eisens besserte sich die Engathmigkeit auffallend, verschwand jedoch nicht vollständig. Das Sehen besserte sich auch etwas. Im Frühjahr viel Kopfweh; Engathmigkeit wieder stärker, sodass Patientin kaum vier Schritte weit rasch gehen konnte. Die Drüsen vor dem $\mathrm{Ohr}$ schwollen noch mehr an. Im 
August Soolbadeur, worauf ziemliche Besserung. Drüsen kleiner, Engathmigkeit nimmt ab. Ueberhaupt nimmt die Dyspnoe ganz constant mit der Sehwellnng der Drüsen $a b$ und zu.

Im September wird das Sehen wieder schlechter. Status: Patientin blass, gut genahhrt. Beiderseits hinter dem aufstoigenden Ast des Unterkiefers grosse Drüsenknollen, fast faustgross. Unter dem Kiefer einige kleine Knoten. Vorn am Hals fühlt man jederseits der Trachea, besonders auf der rechten Seite derselben mehrere geschwellte Lymphdrüsen von harter Consistenz. Sie scheinen die Trachea etwas nach hinten zu verdrăngen. Keine Schluckbeschwerden. Lungenbefund normal. Herz und Leber gleichfalls. Milzdämpfung dentlich vergrössert, besonders in der Breite. Die Dämpfung ist sehr intensiv, etwa $8 \mathrm{~cm}$. lang und $6 \mathrm{Cm}$. breit. Augen bieten beiderseits das Bild der Iritis serosa, rechts aber finden sich jetzt 10-12 hanfkorngrosse Geschwülstehen von graulich - durchscheinender Furbung auf der Iris. Dieselben liegen im unteren Theil der vorderen Kammer haufenweise bei einander. Vollständiger Pupillarabschluss bei nicht ganz enger Pupille. Links dieselben Geschwülstchen wie rechts, nur etwas weniger zahlreich und mehr isolirt stehend. Nach unten eine Gruppe von Knötchen, über die ein neugebildetes, ziemlich grosses Gefäss hinwegzieht. Das Sehvermögen ist beiderseits bis auf Fingerzăhlen in 10-12' reducirt. Keine Zeichen von Syphilis zu finden. Die ofters vorgenommene Untersuchung des Blutes lässt auch Leucämie ausschliessen. Ord. Sehwitzcur.

9. October. Kleines Hypopyon rechts, die Engathmigkeit eher goringer.

31. Oetober. Nene grosse Knötehen bilden sich auf der Iris rechts.

1. November. Wieder Hypopyon rechts, das am 5. verschwunden.

12. November. Links sind die Knötchen auf der Iris im Rückgang begriffen. Drüsenschwellung dagegen bedeutend.

23. November. Syrup. ferr. jod. Krăftige Nahrung. Es ist beiderseits der intraoculare Druck etwas erhöht.

7. December. Rechts wieder leichtes Hypopyon.

12. December. Rechts Paracenthese. Es wird trüber Humor aqueus entleert. 
14. December. Rechts $\mathrm{S} \frac{1}{20}$, L. $\frac{1}{7}$.

15. bis 24. December. Rechts wird der Humor aqueus wieder trüb.

28. December. Beiderseits ein geringes Hypopyon.

8. Januar 1869. Rechts wird der Humor aqueus immer heller.

11. Januar. Links mit $+18 \mathrm{~s} \frac{1}{3}$, Stenop. $\frac{1}{2}$;

$$
\text { Rechts mit }+16 \mathrm{~S} \frac{1}{7} \text {. }
$$

12. Januar. Rechts sind die Irisknötchen fast vollkommen versehwunden. Links hellt sich der Humor aqueus immer mehr anf und die Knötchen nehmen an Grösse ab.

29. September 1870. Beiderseits Pupillarexsudate in Resorption begriffen, dagegen bildet sich rechts eine bandförmige Epitheltrübung der Hornhaut im unteren Dritttheil. Beiderseits Hyp. $\frac{1}{48}$, S Links $\frac{2}{3}$, R. $\frac{1}{2}$. - Das Befinden ist sehr gut, nur die Lymphdrüsen vor der rechten Parotis sind immer noch geschwellt. Irisknötehen verschwunden.

Bei dieser Patientin und ebenso bei der folgenden ist natürlich eine andere Auffassung der Irisknötchen sehr wohl möglich. Man könnte bei Fall Nr. 7 in Anbetracht der vergrösserten Milz und der Drüsenschwellungen an pseudoleucämische Producte denken und bei Patient Nr. 8 an eine lymphomatöse Neubildung. So lange aber wirkliche pseudoleucämische Knötchen oder Lymphome auf der Iris mikroskopisch nicht nachgewiesen sind, dürfen wir wohl - allerdings mit aller Reserve - Neubildungen wie bei Nr. 7 und 8 geschilddert, unter die rückgängige Form der Iristuberculose aufnehmen.

8) Maria M., 13 Jahre alt, erkrankte Ende Februar 1871 ziemlich rasch. Prof. Horner constatirte am 5. März Iritis serosa. Die Drüsen vor dem Ohr und am Kieferwinkel beider- 
seits stark hyperplastisch. Anämisches, schlecht aussehendes Individuum. - Atropin, Tinet. ferri pomata.

8. April. Die Patientin kommt tåglich zur Atropinisirnng ins Spital.

28. October. Seit 4 Wochen besteht in der rechten Iris nach aussen - oben ein getreidekorngrosses, gelblich-weisses Geschwülstehen. Glaskörper nicht getrübt. Rechter 0pticus etwas geröthet. Ol. jecor. aselli.

9. Januar 1872. Das Geschwülstehen in der Iris besteht noch. Die Drüsenschwellung vor dem Ohr geringer. Ord. mit Ol. jecor. fortfahren.

März 1872. Das Knötchen ist ganz klein und durchsichtig geworden und von den Irisfasern kaum mehr za unterscheiden. An der Stelle; wo es sich befand, ist die Iris normal. Beschläge der Hinterwand fast ganz verschwunden.

8. April. Hyp. $\frac{1}{36}$. S 1 beiderseits. - Die Drüsenschwellung vor dem $0 \mathrm{br}$ und am Unterkiefer ganz verschwunden. Rechts noch einige punktförmige Beschläge der Hinterwand der Hornhant. Pupille nach aussen-oben etwas verzogen in der Richtung, wo dass Knötehen gesessen hatte. An der Stelle desselben erscheint jetzt die Iris etwas weisser, dichter, wie vernarbt. Keine peripheren Chorioidalerkranknngen.

9) Carl Z., 12 Jahre, erkrankte im September 1876 und stellte sich am 14. November vor. Er ist ein kleiner, blasser Knabe, im Uebrigen gesund, hustet nicht, leidet hier und da an Kopfschmerz und Hitze im Kopf. Keine Anhaltspunkte für Syphilis.

Status: S R. $\frac{5}{6}$, L. $\frac{1}{20}$. Die linke Pupille ist verengt, quer oval, zeigt zahlreiche Synechien und ein flaches Pupillarexsudat; tiefe vordere Kammer. Iris ciliarwärts zurückgedrängt, zeigt ans der Tiefe des untern Falzes anfsteigend, eine Anzahl grau-röthlicher Geschwülstchen, von Gefässen durchzogen*). Zwei sehr grosse, confluirte sitzen gerade nach

*) Form und Färbung dieser Geschwülstchen ist ganz dieselbe wie in Fall Nr. 17, wo die milkroskopische Untersuchung auf's Deutlichste die tuberculöse Natur der Wucherung feststellte (vergl. pag. 115). 
unten, mehrere kleine nach innen und aussen-oben. Ganz nahe dem inneren-unteren Pupillarrand steigt aus der Fläche der Iris ein kleines graues, etwas durchscheinendes Knötchen hervor, das vollständig einem Miliartuberkel gleich sieht. In der Iris zahlreiche ausgedehnte Gefässe sichtbar, die geschlängelt von der Peripherie zum Pupillarrand gehen. Zahlreiche Beschläge auf der Hinterwand der Cornea im unteren Bereich derselben. T. beiderseits gleich, normal. Keine Drüsenschwellungen vor dem $\mathrm{Ohr}$ und am Unterkiefer, dagegen findet sich auf der rechten Nackenseite eine Reihe geschwellter, kleinerer Drüsen. Diagnose: Granuloma iridis. - Eine längere Behandlung mit Jodkali, guter Nahrung, Ol. jecor. u. s. w. bessert den Zustand des Auges nicht wesentlich.

Don 15. August 1878, also fast 2 Jahre nach Beginn der Krankheit, ergiebt eine neve Untersuchung des Patienten, der sich weiterer Behandlung entzogen hatte (übrigens auf dem Lande lebt) Folgendes: Auge ruhig, nur bei stärkerem Gebrauch der Augen sich hier und da leicht röthend (ebenso bei der Untersuchnng). Dasselbe war bis zur Stunde nie schmerzbaft gewesen. Patient war immer gesund, hustet nicht, sieht aber blass aus und ist für sein Alter klein und schmächtig. Der linke Bulbus ist in toto etwas kleiner, leicht vierseitig abgeplattet durch die Recti. Die Cornea ist verkleinert, queroval. Der untere Quadrant derselben leicht bläulich getrübt, besonders in den hinteren Lamellen. Ein Durchbruch der Geschwulst nach aussen hat nicht stattgefunden. Dieselben sind vielmehr total verschwunden. Die vordere Kammer ist ganz seicht, die Iris atrophisch. Einzelne kurze, zarte, membranöse vordere Synechion von graulicher Farbe spannen sich namentlich im unteren Theil der vorderen Kammer und temporalwärts von der Pupille zwischen Vorderfläche der Iris und Hinterwand der Cornea aus. Eine etwas derbere vordere Synechie findet sich nahe dem oberen Pupillarrand (NB. es war nie paracenthesirt worden). Auch die punktförmigen Beschläge anf der Hinterwand der Cornea sind gänzlich verschwunden. In der kleinen, unregelmässigen Pupille ist eine lebhaft weisse Capseleataract sichtbar, die durch hintere Synechien, namentlich nach oben, mit dem Pupillarrand verlöthet ist. Der Bulbus ist ganz weich, anf Druck nicht schmerzhaft. Projection gut. Patient unterscheidet Handbewegungen auf 2\%" - Das Verschwinden 
der Knötchen auf der Iris hat sich, zugleich mit den entzündlichen Erscheinungen, ohne weitere eingreifende Behandlung von selost vollzogen. Für die Annahme ron Syphilis sind auch jetzt absolut keine Anhaltspunkte vorhanden.

10) Jeanne B., 7 Jahre alt, erkrankte im December 1876, indem das linke Auge sich stark röthete, lichtscheu wurde und rasch das Sehvermögen bis auf Lichtschein verlor. Dabei Schmerz im Auge und allgemeines Uebelbefinden. Schon vor der Entzündung des Auges war die Patientin sehr blass gewesen, litt an Drüsenschwellungen, Katarrhen etc. - Im Mai 1877 sah Prof. Horner das Kind. Er diagnosticirte Granuloma iridis and verordnete entsprechende Allgemeinbehandlung und Atropin. Patientin machte einen längeren Landaufenthalt, worauf sich bald das Aussehen und Befinden besserte. Ein Durchbruch der knötchenförmigen Wucherungen nach aussen fand nicht statt, sondern es gingen dieselben, wie im vorigen Fall vollständig zurück und wie dort findet man gegenwärtig auch dieses Auge im Zustand der Atrophie, vierseitig abgeplattet, reizlos, auf Druck nicht schmerzhaft. Die Iris ist atrophisch. Pupillarverschluss. Lichtschein verschwunden. Das rechte Auge ist ganz gesund.

Auch in diesem Fall liegt nichts vor, was zur Annahme von Syphilis berechtigen würde, dagegen starb der Vater vor einem Jahre an Lungentuberculose und der Bruder des Vaters an einer (wahrscheinlich tuberculösen) Meningitis. Das Kind zeigt keine verduchtigen Symptome von Seiten der Athmungsorgane. Seit Ablauf der Affection am Auge hat sich das Allgemeinbefinden in auffallender Weise gehoben.

11) Leonore L., 16 Jahre alt, kam zu mir am 17. September 1878 mit dem Bild beiderseitiger heftiger Iritis, die seit 3 Wochen bestehen soll.

Von Jugend an war Patientin nie recht gesund, litt vielfach an Eczem, Husten, Drüsenschwellungen. Der Husten und die Engathmigkeit hat in den letzten Jahren zugenommen. Der sie deshalb behandelnde Arzt hatte wegen des Zustandes der Lungen den Angehörigen gegenüber eine schlechte Prognose gestellt und man glaubte sogar kaum, dass sie den vergangenen Winter überleben werde. - Gegenwärtig bietet Patientin ein anämisches, gedunsenes Aussehen. Unter dem rechten 
Unterkieferwinkel findet sich ein grosses Drüsenpaquet; linke Halsseite, sowie die Clavicular- und Axillargegend beiderseits frei von Drüsenschwellungen. Bei Untersuchung der Lungen fand ich Infiltration der ganzen linken oberen Lungenpartie und ausgebreiteter Catarrh der feinen Bronchien im ganzen oberen Theil beider Lungen. Keine Anzeichen von Cavernen. Absolut keine Anhaltspunkte für Syphilis.

Die Iritis beiderseits bochgradig. Zahlreiche Beschläge auf der Hinterwand der Cornea (unterer Quadrant), Trübung des Humor aqueus und zahlreiche Synechien, jedoch ohne vollständigen Pupillarabschluss. Links im nntersten Theil der vorderen Kammer eine noch nicht stark aus dem Cornealfalz emporragende graulich - rothe Masse, von der kaum zu unterscheiden, ob sie als ein Exsudat - Dépôt oder als eine Wucherung aufzufassen; die mehr röthliche Färbung spricht für letzteres. Beiderseits Opticas kaum sichtbar. S R. $\frac{1}{5}, \mathrm{~L} \frac{1}{5}$ bis $\frac{1}{4}$. - Ord. Atropin, Dunkelbrille. Eisen mit Chinin. Kräftige Nahrung, frische Luft und da die starke Entzündung nicht abnimmet, bald darauf Ungt. ciner. 2 Mal täglich in Stirn und Schläfe einzureiben. - Am 4. October wird der Medication noch Leberthran beigefügt. Am 9. October ist zwar die pericorneale Richtung rechts fast ganz verschwunden, links nur noch sehwach, aber es hat sich links, während die Beschläge auf der Hinterwand der Cornea auch abnahmen, aus dem unteren Cornealfalz herans nach und nach eine ziemlich grosse, grau-rothe, mit feinen Gefässen versehene, knötchenformige Wucherung entwickelt, die auf der stark injicirten Iris sitzt. Rechts fangen ebenfalls aus dem untersten Theil der vorderen Kammer an knötchenförmige Wucherungen aufzuwachsen. - 14. October. Beiderseits Pericornealinjection stärker, besonders links ganz beträchtlich, hauptsächlich nach unten von der Cornea. Die Beschläge auf der Hinterwand beiderseits vermehrt, aber keine weiteren Synechien.

21. October. Rechts haben die graulich - rothen Wucherungen zugenommen und links ist ein neues kleines Knötehen neben den früheren entstanden, ebenfalls im unteren Falz und zwar nasalwärts von diesen.

Ord. Statt Chinin and Eisen jetzt Jodeisen. Uebrige Behandlung gleichbleibend; nur wird zeitweise Ungt. ciner. auf 
Stirn und Schlafe ausgesetzt, so dass nie Salivation eintritt. - 5. November. Status idem. T. beiderseits normal. Die Wueherungen haben in letzter Zeit beiderseits immer noch etwas zugenommen. Dagegen ist das Lymphdrüsenpaquet vor dem rechten $\mathrm{Ohr}$ entschieden kleiner geworden. Immer treten ab und zu Schmerzen auf, die durch warme Umschläge gemildert werden. Starke Reizerscheinungen.

12. November. Bei gleich bleibender Behandlung: Iris beiderseits immer roch stark hyperämisch. Die knötehenförmigen Wacherungen links entschieden etwas kleiner, rechts keine Zunahme derselben. - 15. Norbr. Knötchen beiderseits im Rückgang, anch die Reizerscheinungen geringer. 19. Novbr. Die Knötchen ragen kaum mehr aus dem Falz heraus. - 25. Novbr. Pericorneale Injection links ganz unbedeutend, rechts ganz verschwunden. Rechts ist ron den Wucherungen fast nichts mehr zu sehen; das grösste Knötchen links ist kaum mehr $1 / 4$ so gross wie früher, Iris viel weniger hyperämisch. Beiderseits noch Beschläge auf der Hinterwand der Cornea, aber weniger dicht und Humor aqueus viel klarer. Keine Schmerzen mehr.

29. Norbr. Das grösste Knötchen links ist kaum mehr zu sehen, diejenigen rechts sind ganz verschwunden. Dabei sieht Patientin viel besser aus, hustet aber immer. Trotz einiger neuer entzündlicher Nachschübe, aber ohne das wieder jene Knötchen sich zeigten, beruhigen sich nach und nach die Augen immer mehr, so dass am 14. Januar 1879 das rechte Auge ganz weiss ist, das linke nur eine Spur pericornealer Richtung nach unten zeigt. Dagegen lassen sich jetzt, da der Einblick mit dem Ophthalmoskop leichter ist, nebst leichter Röthung beider Papillen rechts einige rundliche, disseminirte, etwas ältere chorioiditische Heerde ganz peripher nach unten nachweisen. Der Glaskörper beiderseits noch leicht diffus getrübt, ohne grössere Flocken. Linke Chorioidea frei. - Bis in den Sommer dieses Jahres wird abwechselnd mit Jodeisen, Eisen mit Chinin, 0l. jecor., Kempten - Sulzbrunner Wasser, kräftiger Nahrung, Schonung der Augen ete. fortgefahren, wobei $a b$ und zu etwas pericorneale Injection bald rechts, bald links wieder auftritt und ebenso hier und da Zunahme der Beschläge and Trübung des Humor aq. Doch werden rom $\mathrm{Mai}$ an die Augen immer ruhiger. Am 28. Mai: Beiderseits keine pericorn. Injection. 
Lymphdrüsen vor dem rechten $\mathrm{Ohr}$ viel kleiner. Atropin wird jetzt weggelassen. - 23. Juli. Keine Röthung beiderseits. R. M 1 D. $S \frac{2}{3}$ bis $\frac{5}{6}$. L. M 1 D. $S \frac{5}{6}$. - Rechts Glaskörper fast von normaler Klarheit, aber doch ist ein neuer kleiner chorioiditischer Heerd, nicht ganz frisch, zu constatiren und links findet sich jetzt ein ähnlicher kleiner, ebenfalls scharf begrenzter rundlicher chorioiditischer Heerd, ebenfalls peripher. Pat. hat in letzter Zeit nur noch KemptenSulzbrunner Wasser getrunken (ca. 15 Flaschen), womit fortgefahren werden soll. War auf dem Land, trinkt viel Milch.

Bezüglich dieses interessanten Falles ist darauf hinzuweisen, dass allerdings der so befriedigende Erfolg der Behandlung den Verdacht ruft, es möchte sich hier um Syphilis handeln. Es spricht aber so Vieles dagegen: die ganz periphere Lage der Wucherungen auf der Iris, die Färbung derselben, die Abwesenheit ausgebreiteter Drüsenschwellungen, das Fehlen aller Knochenaffectionen, kurz aller für Syphilis charakteristischer Merkmale, dass man wohl Syphilis excludiren darf. Auch ist das Aussehen der chorioiditischen Heerde anders, als bei der manchmal in der Peripherie bei Syphilis zu constatirenden Chorioiditis. - Für Tuberculose aber spricht in hohem Grade die Lungenerkrankung.

\section{Gruppe.}

12) Jakob Sp., 5 Jahre, kam am 25. Marz 1870 zu Prof. Horner wegen Erkrankung des linken Auges, das seit drei Wochen wieder entzündet, nachdem Patient um's Neujahr die Masern und 14 Tage darauf eine Entzündung des linken Auges durchgemacht, die wieder zurückgegangen war. Im Herbst vorher Abscess unter dem Arme. - Status: Blondes, zartes Kind. Die Submaxillar-Drüsen links und die rechte Tonsille stark geschwellt. Linke Cornea leicht trüb, chagrinirt. Die vordere Kammer fast ganz aufgehoben 
in Folge röthlicher, granulationsartiger Wucherungen auf der Iris, die besonders nach anten - aussen stark sind und an die Hinterfläche der Cornea sich anpressen. Bulbus weich.

31. März. Iris stärker vorgedrängt, Seleralzone nach oben ausgedehnt, ectasirt. Schmerzen.

4. April. Unruhiger Schlaf. In Pupillargebiet dicker resiatenter Eiter.

10. April. Ausbuchtung der ganzen Corneo-Scleralzone enorm in Zunahme begriffen.

12. April, Vom Irisgewebe, fast nichts mehr zu entdecken. Iris nach unten in eine eitrige Masse verwandelt.

18. April. An drei Stellen nach unten-innen tritt eine grau - röthliche, weiche Granulationsmasse in der Scleralzone hervor. Kein Sehmerz, Schlaf ruhiger.

21. April. Bulbus wird immer weicher. Drei grosse Perforationsstellen mit röthlicher, zitternder oedematöser Granulationsmasse. Cornea überzieht sich immer mebr mit Gefässen.

7. Mai. Die perforirten Stellen ziehen sich zusammen.

15. Mai. Die Schrumpfung geht weiter.

18. Juli. Bulbus sehr weich. Die Geschwulstpartie flacht sich immer mehr ab. Cornea nach aussen und oben durchscheinend. Die mikroskopische Untersuchung der abgekappten Granulationen ergab in denselben zahlreiche Tuberkelknötchen. Dabei war aber auch das Granulationsgewebe stark entwickelt und das Bild dieser Affection ähnelte bezüglich der Vertheilung von Tuberkel- und Granulationsgewebe mehr den Befunden bei der Conjunctivitis tubereulosa.

Der Vater des Knaben starb im Jahre 1871 an Phthisis und mehrere andere Glieder seiner Familie sind oder waren Phthisiker. Nachforschungen nach dem jetzigen Befinden des Patienten ergaben, dass derselbe jetzt (also ca. 8 Jahre nach Beginn der Erkrankung) ein kräftiger, grosser Bursche geworden ist. Das linke Ange sei total erblindet, das reehte gesund geblieben. Auch sonst sei er gesund und nicht lungenkrank.

13) Elisabetha B., 8 Jahre alt, stellt sich im Februar 1872 zum ersten. Mal vor. Es war im Herbst 1871 das rechte Auge von Entzündung und Röthung befallen worden, welcher Zustand sich ohne Schmerzen mit geringen Schwan-

v. Graefe's Archiv far Ophthalmologie, XXV. 4. 
kungen bis jetzt erhalten hat. Patientin war früher immer gesund. Leichte Drüsenschwellungen unter dem Kiefer. Das Kind erscheint gut genährt, nicht anämisch. Linke Iris schön hellblau. Rechtes Auge nach innen - oben gestellt (nach Aussage des Vaters seit 14 Tagen) ohne Protrusion und ohne Beweglichkeitshemmung desselben. Bulbus weich, auf Druck nicht empfindlich. Pupille vollkommen eng und durch Exsudat verschlossen. Die Iris ist in ihrer Totalität in eine gelblich - röthliche, höckerige, dicke Masse verwandelt, welche bis an die Hinterwand der Cornea stösst und sich an derselben etwas abflacht. Bei seitlicher Beleuchtung und Loupenvergrösserung bemerkt man neben starker Gefässausdehnung und allseitiger Schwellung der Iris hauptsächlich 3 Stellen mit starker, graulich - durchscheinender Geschwulstbildung, eine nach unten, eine nach aussen und eine nach innen-oben. Lichtschein and Projection ziemlich gut. Keine Anhaltspunkte für Syphilis.

Diagnose: Granuloma iridis. Ord.: Jodkali.

27. Februar. Status idem.

6. März. Status idem. Allgemeinbefinden gut.

7. März. Iridectomie nach innen - unten. Es ist schwer, die Geschwülstchen zu fassen, indem sie immer ausweichen. Endlich golingt es ihrer drei zu extrahiren (gingen leider verloren). Die Iris, auf der sie sitzen, wird mit ausgeschnitten. Die neugebildete Pupille wird aber sofort wieder von den umliegenden Geschwulstmassen aberlagert.

10. März. Patientin steht auf, es geht gut.

15. März. Die neue Pupille ist wieder vollständig geschlossen.

24. März mit Jodsalbe entlassen.

Erkundigungen, die ich in jüngster Zeit über die (weit entfernt wohnende) Patientin einzog, ergaben (am 18. August 1878, also 6\% Jahre nach Beginn der Erkrankung), dass das Auge den Lichtschein verloren hat und sich hier und da entzündet. Das andere Auge ist gesund geblieben. Das Mädchen sei gut entwickelt, habe ein $\mathrm{Mal}$ eine leichte Lnngenentzündung gehabt. Im Herbst und Frühling leide Patientin regelmässig an Bronchialcatarrh, ferner seien Athembeschwerden auch bei mässigem und langsamem Steigen vorhanden. 
14) Rosalie A., 18 Jahre alt. Kam am 8. Novbr. 1872 zu Professor Horner. Seit 10 Wochen ist das rechte Auge erkrankt, das vorher immer gesund gewesen war. Keine Zeichen von Syphilis. Starke Struma und Engigkeit. Rechte Iris verdickt, von reichlichen Gefässen durchzogen, an die Hinterwand der Cornea angedrängt. Pupille unregelmässig, adhärent. Pupillarrand ebenfalls verdickt und stellenweise grawweiss. Zahlreiche Beschläge auf der Hinterwand der Cornea. Unterhalb des unteren Cornealrandes im VerticalMeridian zwischen Cornea und Rectus inferior zeigt sich eine erbsengrosse Erhabenheit, deren Spitze von einem schmutziggrau-gelben Krater eingenommen wird. Conjunctiva bis an den Rand des Kraters intakt. Sclera ausgedehnt. Der kleine Tumor ist elastisch. Lichtschein gut. Diagnose: Granuloma corpor. ciliar. ot Selerae. Ord.: Heilbrunner Adelheidwasser 2 Glas pr. die.

23. November. Umfang des Kropfes von 39 auf $37 \mathrm{Cm}$. verkleinert. Die im Durchbruch begriffene Geschwulst hat etwas abgenommen.

15. Januar 1873. Es wird trotz nicht vollständiger Vernarbung des Ciliar-Granuloms der Versuch einer Iridectomie gemacht. Wie vermuthet worden, gelang es nicht, die Iris zu fassen, da sie zu fest an der Linse adhärent war. Sofortige Erweiterung des Schnittes (Linearmesser) und Ausschneiden der Iris mit der Scheere in Auge drin mit Entleerung der Linse.

19. Januar. Ziemlich starke eitrige Secretion, untere Partie der Cornea ziemlich stark getrübt.

10. Februar. Entlassen.

4. März. Lichtschein auf 3'. Projection schlecht.

15) Johannes W., 16 Jahre alt, erkrankte im October 1871 an starken Drüsensehwellangen am Hals und im November begann die Erkrankung des linken Auges. Zugleich litt er viel an Husten, grosser Engigkeit, Appetitmangel und war eigentlich den ganzen Winter 1871/72 nie recht wohl. Im März 1872 war das linke Auge mittlerweile erblindet nnd es begann jetzt die Entzündung des rechten Anges. Im Mai stellte er sich zum ersten Mal Prof. Horner vor. - Status: Links Lichtschein auf $10^{\circ}$. Projection ganz sehlecht. Fechts 
S kaum $\frac{1}{20}$. Beide Bulbi ziemlich weich, der linke mehr als der rechte. Links sehr ausgedehnte Ciliargefässe. Cornea zeigt zahlreiche Beschlige auf der Hinterwand und ist stark vascularisirt. Die Pupille ist nur als ganz schmaler, querer Sehlitz sichtbar, der von innen - oben nach anssen- unten verläuft. Der untere - innere und der obere Quadrant der Iris sind in grosse, grau - röthliche, gefässreiche Geschwülste umgewandelt, welche der Cornea ganz anliegen, die Pupille auf besagte Spalte zusammendrängend. Im äusseren Quadranten der Iris sind nur wenige, kleine grau-röthliche Knötchen sichtbar, - Rechts ist die Hinterwand der Cornea ebenfalls mit zahlreichen Beschlägen von theilweise ausserordentlich grossem Umfang bedeckt. Die Iris erscheint verdickt, zahlreiche Synechien am Pupillarrand. In der Peripherie der Iris finden sich vier grau - röthliche Geschwulstknötehen mit reichlichen Gefässen in ihren oberflächlichen Schichten. Das grösste dieser Geschwülstchen von ca. $4 \mathrm{Mm}$. Länge und $2 \mathrm{Mm}$. Breite befindet sich direct nach aussen und zwei stecknadelkoptgrosse liegen nnmittelbar unterhalb derselben. Das vierte stecknadelkopfgrosse Knötchen befindet sich nach innen-oben. Beide Thränendrüsen sind stark geschwollen, so dass diejenige rechts stark in's Bereich des oberen Lides hineinragt.

Die Untersuchung der Lungen ergiebt beiderseits oben, besonders rechts, Dämpfung. Rechts oben ist amphorisches Athmen, vorhanden, unten zahlreiche Rasselgeräusche. Links äberall sibilirende, starke Rasselgeräusche.

Patient entzieht sich weiterer Beobachtung. Nachforschungen nach demselben, in jüngster Zeit erhoben, ergaben, dass derselbe noch lebt, ein Auge, (wahrscheinlich das linke), anderwärts enucleiren liess, am andern Ange noch etwas Lichtschein habe and im Uebrigen wohl (?) sei.

16) Friedrich K., 5 Jahre alt, wurde am 24. September in die Graefe'sche Augenklinik (Halle) gebracht und in A wesenheit von Prof. Graefe ron dem Assistenzarzt Doctor Fränkel untersucht. Es ergab sich: eine starke Trübung der rechten Cornea, welche nur wenig mehr durchsichtig ist, sodass die Iris undeutlich gelb hindurchsehimmert. Dabei starke, pericorneale Injection. Ob noch Lichtschein vorhanden, konnte nicht festgestellt werden. Das Uebel hatte kurz nach 
Weihnachten des vorigen Jahres mit lebhaften Schmerzen begonnen, worauf ziemlich bald das Sehvermögen verloren gegangen sein soll. Das Kind sei bis dahin sonst gesund gewesen. Der Vater starb vor 2 Jahren an Lungen - Phthise. Die Mutter ist gesund. - Im November brachte die Mutter das Kind wieder in die Klinik. Die Cornea ist jetzt vollstăndig undurchsichtig, der vordere Abschnitt des Bulbus sehr stark hervorgetrieben", das Auge äusserst schmerzhaft. Prof. Graefe nahm die Enueleation vor. Die Heilung erfolgte schnell und normal.

Der in Müller'scher Flüssigkeit conservirte und gehärtete Bulbus wurde von Prof. Steadener mikroskopisch untersucht. Ich lasse hier den noch nicht veröffentlichten Befund, welchen mir Prof. Graefe und Prof. Steudener freundlichst zur Verfügung stellten, in extenso folgen. Nach Eröffnung des Bulbus durch Horizontalschnitt fand sich die Iris um das 5-6 fache verdickt, mit unregelmässiger, kleinhöekeriger Oberfläche in die vordere Kammer hineinragend und sammt einer, diese vordere Fläche bedeckenden Exsudalschicht dieselbe fast ganz ausfüllend. Der Ciliarkörper ist gleichfalls von einer grau-gelblichen Gewebsmasse durchsetat, die in die anliegende Sclera vordringt. An Linse, Glaskörper, Retina und Chorioidea ist nichts Abnormes zu sehen. - Ein durch Hornhant, Iris und Ciliarkörper gelegter Schnitt zeigte bei schwächerer Vergrösserung eine Trübung der Cornea, welche am Scleralrande am stärksten war, im Centrum der Hornhaut dagegen nur die oberflachlichen Schichten betraf und in einer Infiltration (Immigration) derselben durch granulirte Rundzellen bestand. Am Seleralrande hatten sich büschelförmige Züge von Gefässen in die Cornea hinein geschoben. Sie reichten in den vorderen Cornealschichten am weitesten gegen das Centrum der Hornhaut hin. Die episcleralen Gefässe zeigen in der Nähe des Scleralrandes eine beträchtliche Erweiterung. Stärkere Vergrösserung ergiebt, dass die Rundzellen in den erweiterten Saftcanälehen der Cornea gelegen sind. - Das eigentliche Stroma der Iris und das Corpus ciliare verschwindet fast vollständig unter der Entwickelung der erwähnten neugebildeten Gewebsmasse und nur einzelne kleine, durch ihren Pigmentgehalt kenntliche Gewebspartien sind dazwischen zerstreut sichtbar. Stärkere Vergrösserung zeigt innerhalb des neugebildeten Gewebes eine Gruppirung in ein- 
zelne kleinere und grössere Knötchen, welche theilweise ein ziemlich opakes Centrum besitzen. Zwischen den Knötchen sind, namentlich im Ciliarkörper, einzelne oder gruppenweise beisammenstehende Pigmentzellen zerstreut, von welchen an manchen Stellen einzelne Knötchen vollständig ringförmig umgeben sind. Die grösseren Knötchen zeigen ein durchaus verkästes Centrum, während in der Mitte der kleineren, jüngeren regelmässig ein oder mehrere grobkörnige, mit Ausläufern versehene Protoplasmahaufen, welche eine grosse Zahl meist radiär gestellter ovaler Kerne enthalten (Riesenzellen) gefunden werden. Aus den Protoplasmafortsätzen entsteht ein alveolares Netzwerk, welches an einzelnen Stellen in den Knotenpunkten Kerne erkennen lässt. In den Alveolen dieses Netzes findet man grosse, epitheloide, kernhaltige Zellen eingelagert, so dass je eine Zelle eine Alveole ausfüllt. Mehr peripherisch finden sich dann in einem feinfaserigen Reticulum granulirte, kernhaltige Rundzellen eingelagert. Demnach bosteht jedes Knötchen aus einer centralen, sog. Riesenzelle, einer Zone darum gelegener epitheloider Zellen und zu äusserst aus kernhaltigen, granulirten Rundzellen.

Dieser Schilderung des mikroskopischen Befundes von Prof. Steudener habe ich nur wenig beizufügen. Als ich einige Zeit nachher den Bulbus ebenfalls zu untersuchen Gelegenheit hatte, konnte ich die knötchenförmige Neubildung ebenfalls nur für Tuberkel halten, in vielen Punkten den Bildern ähnlich, wie man sie in kleineren conglobirten Tuberkelknoten des Gehirns oder in tuberculösen Hoden zu treffen pflegt. - Sehr schön lässt sich gerade an diesem Bulbus das allmälige Vordringen der Tuberkelknötehen in die Sclera hinein verfolgen. Zuerst wird das Gewebe derselben durch kleinere und grössere Haufen von Rundzellen, die sich in die Gewebsspalten zwischen den Faserlagen dieser Membran hineindrängen, aufgelockert und anfgefasert. Diese Zellenhaufen erscheinen meistens länglich, spindelförmig, aber auch unregelmässig. Woher sie stammen, ob es wejsse Blutkörperchen oder Abkömmlinge der granulirten, zu äusserst liegenden Zellen des Tuberkels sind, ist nicht ganz sicher. An einer Stelle der so veränderten Sclera sieht man ganz kleine, junge Tuberkel schon bis fast zur Conjunctiva bulbi hin vordringen und der Durchbruch daselbst stand somit vor der Thür. Was das Corpus ciliare betrifft, so sind hauptsächlich die Ciliar- 
fortsätze, welche ungemein vergrössert und infiltrirt sind, Sitz der Tuberkelbildung, während der Ciliarmuskel nicht so stark damit durchsetzt und etwas nach hinten gedrängt ist. - Das von Steudener gesehilderte Verhältniss der Riesenzellen zum Reticulum des Tuberkels dagegen konnte ich mir nicht in überzeugender Weise zur Anschauung bringen, weder an diesem Präparate, noch bei den übrigen Untersuchnngen über Tuberculose. Wenigstens als Regel möchte ich dies Verhalten nicht hinstellen. Ich sah allerdings auch häufig feine Protoplasmaausläufer der Riesenzellen zwischen den umliegenden epitheloiden Zellen sich verlieren, eben so häufig aber bemerkte ich an den Riesenzellen entweder gar keine Fortsätze, oder sie fanden sich nur an der einen Seite, während die übrige Contour ziemlich glattrandig war. Ich möchte nicht einmal behaupten, dass sich in allen Tuberkeln ein Reticulum findet. Gewiss fehlt dasselbe zum Beispiel in ganz jungen, noch kleinen Knötchen häufig und es ist fraglich, ob es nicht überhaupt ein Kunstproduct ist.

17) Darid D., 8 Jahre alt, trat am 31. März 1877 in die Behandlung von Prof. Horner. Der kleine, schwächlich aussehende Junge, welcher noch nie krank war, aber anämisch aussieht, leidet seit 9 Wochen an einer Erkrankung des linken Auges, die mit einem kleinen Fleckchen auf der Regenbogenhaut begonnen habe.

Status: Bulbus etwas hart, leichte Ciliarinjection, vordere Kammer aufgehoben. Die Iris verfärbt, liegt mit 3 Quadranten der Cornea an, während der Pupillarrand an der Linsencapsel adhärent ist. Der untere äussere Quadrant der Iris ist in eine grau - röthliche, etwas höekerige Geschwulst verwandelt, in welcher gelblich-undurchsichtige mit röthlich-grauen Stellen abwechseln. Bei seitlicher Beleuchtung sieht man, dass die Geschwulst nicht bloss die vordere Kammer einnimmt, sondern die Linse zurückzudrängen scheint und wahrscheinlich die Vorbauchung der übrigen Iris davon herrührt, dass die Geschwulst hinter ihr wächst. Es droht Gefahr des ciliaren Durchbruches nach unten - aussen. Pat. zählt noch Finger in 2月'. - Am 29. Juni stellt sich der Knabe wieder vor. Status idem. Ord. Liq. arsenical. Fowl.

7. Juli. Lichtschein auf 6-8'. Status idem. Enucleatio bulbi. Heilung normal. 
Die anatomische Untersuchung dieses sehr interessanten Bulbus ergiebt eine tiberraschende Aehnlichkeit mit dem eben geschilderten Befund in Fall Nr. 16. Während aber dort die Iris ringsherum von dem tuberculösen Process ergriffen wurde, ist dies hier nur im unteren - änsseren Quadranten der Fall, während der übrige Theil der Iris bloss in Folge des Pupillarabsehlusses bis an die Hinterwand der Cornea vorgebaucht und sammt dem ihr entsprechenden Theil des Corpus ciliare nicht wesentlich afficirt ist (vergl. Tafel II, Fig. 1). Nur eine mit der Irisvorwölbung und der dadurch bedingten Dehnung correspondirende geringgradige Atrophie dieser Membran ist $\mathrm{zu}$ bemerken. Hochgradig verändert ist dagegen der gegenüberliegende Theil des Corpus ciliare sammt daran grenzender Iris. Diese Gebilde sind um das zehnfache verdickt und es stösst hier tuberall Knötchen an Knötchen. (Fig. 1, T. $T_{y}$ ). Das ursprüngliche Stroma dieser Theile documentirt sich nur noch stellenweise dureh die zwischen den Tuberkeln liegenden pigmentirten Gewebszüge. Auch hier man, wenigstens im Bereich des ursprünglichen Corpus ciliare und der hinteren Lagen des Iris - Tumors, häufig die Pigmentringe um die Knötchen herum. Doch fehlen auch inmitten der Tuberkel, ja sogar inmitten der Riesenzellen die Pigmentkörnchen nicht. Die vorderen Partien der auf der Iris wuchernden Knötchen dagegen sind fast ganz pigmentfrei. - Im Centrum der Tuberkel trifft man sowohl Riesenzellen, als auch da und dort Verkäsung.

Auffallend ist der Zustand, in dem sich die Linse befindet. Sie hat ihre normale Gestalt eingebusst, ist kleiner, wie geschrumpft und namentlich auf der Seite des erkrankten Corpus ciliare hochgradig verändert. Hier ist nämlich die Continuität der Capsel unterbrochen und eine dichte Lage meist rundlicher Zellen, die sich auf jener Seite zwischen die Linse und das Tuberkelconglomerat einschiebt, schickt Zellhanfen bis weit in die Linsenmasse hinein. Die Linsencapsel ist dort offenbar von den andringenden Zellen usurirt unà durchbrochen worden. Diese Zellen gehören nicht den Tuberkelknötchen an. Sie besitzen das Aussehen indifferenter, granulirter ovaler oder Rundzellen, wahrscheinlich Abkömmlinge von Bindegewebszellen (s. Fig. 4, H.). Dazwischen finden sich auch ausgewanderte farblose Blutkörperchen. Diese Zellschicht schiebt sich namentlich zwischen Corpus ciliare und 
Linse ein und sie ist es, welche wie immer bei der Ausbreitung der Tuberkelneubildung anf ein noch nicht afficirtes Gewebe dieses ergreift und anflockert. (Das analoge findet gegen die Sclera hin statt.) Es erinnert dies etwas an die Art und Weise, wie z. B. ein Cancroid den Knochen angreift. Es sind nicht die Epithelzapfen, welche direct den Knochen zerstören, sondern dies besorgt eine Schichte von Granulationsgewebe, die jene vor sich herschieben. - Der grösste Theil der vorderen und hinteren Capsel ist aber noch vorhanden, etwas gefaltet. Stark wellig verlänft namentlich die vordere Capsel (Fig. 1, LC.) und hinter derselben sehen wir eine typische Capseleataract, d. h. ein streifiges, offenbar schon ziemlich organisirtes Gewebe mit disseminirt darin vertheilten Spindel- und Rundzellen. Einen analogen Befund verzeichnet Sattler (Becker's Atlas, loc. cit.). Nan findet man aber innerhalb des Linsengewebes zweierlei Zellen. Erstens die kleinen, runden, bald mehr-, bald einkernigen Zellen der eben erwähnten Zwischensehicht. Zweitens aber da und dort, besonders mehr in der Tiefe, zwischen den Linsenfasern auffallend grosse, sehr stark granulirte, durchsichtige Zellen, die wie gebläht aussehen (Fig. 4, G.). Sie liegen häufig in Haufen beisammen, öfters aber vereinzelt, zerstreut. Sie ähneln den grossen Zellen, die man in den sogenannten Krystallwülsten findet (Fig. 4, F.), absolut nicht, sind immer ganz regelmässig rund und nicht wie jene vielgestaltig und unregelmässig und sind kanm wie jene Abkömmlinge der Capselepithelzellen. Dagegen macht es ganz den Eindruck, als wären diese sonderbaren Zellen dadurch $z u$ ihrer auffallenden Grösse gelangt, dass sie, ursprünglich gewöhnliche Rund- und Granulationszellen und Abkömmlinge jener die linse ergreifenden Zellhaufen (oder vielleicht farblose Blutkörperchen), innerhalb der Linsenmassen angelangt, den Inhalt der arrodirten Linsenfasern in sich aufgenommen hätten: Sie hïtten sich also gleichsam mit dem Inhalt der Linsenröhren gefüttert, vielleicht weniger deshalb, weil ihnen dieser besonders behagte, sondern wohl lediglich auf endosmotischem Wege. Woun diese Gebilde, die immer einen schönen Kern zeigen, eine gewisse Grösse erreicht haben, bilden sich in denselben Vacuolen und dann gehen sie rasch zu Grunde. Dafür, dass sie den Inhalt der Linsenfasern in sich aufgenommen haben, spricht auch der Umstand, dass man sie am häufigsten zwi- 
schen den zahlreichen Kugeln, welche durch den ausgetretenen Inhalt der Linsenröhren gebildet werden, liegen sieht. Zn bemerken ist, dass in dem Bezirk des Linsenăquators, der gegen das nicht erkrankte Corpus ciliare gerichtet ist, die äquatorialen Capselzellen, wohl wahrscheinlich in Folge der Druckentlastung, stark gewuchert sind und jene Zellformen producirt haben, wie man sie in Krystallwälsten antrifft (Fig. 4, F.). - Auch hier, wie im vorigen Fall, ist die Chorioidea und die Retina frei von Tuberkeln.

18) Frau $P$, 25 Jahre alt, trat am 4. April mit den Erseheinungen einer schweren Iritis serosa des linken Auges in die Behandlung von Herrn Prof. Horner. Die Erkrankung des Auges bemerkte Patientin erst seit einigen Tagen. Sie sei sonst immer gesund gewesen. Die Inspection ergiebt: starke Beschläge auf der Hinterwand der Cornea, sehr bedertende Trübung des Humor aqueus. Pupille frei. Ord. Atropin, Ungt. einer. in Stirn and Schläfe einzureiben (nicht etwa wegen Verdacht von Lues, wozu kein Anhaltspunkt vorlag, sondern wegen der heftigen entzündlichen Erscheinungen).

7. April. Pupille mangelbaft erweitert, Bulbus resistent.

11. April. Am oberen Rand der Pupille eine dicke, weissgelbe Hervorragung, ähnlich einem Gumma.

13. April. Die vordere Kammer um das 5 fache vergrössert (vertieft), Iris und linse in die Tiefe gesunken.

14. April. Schmerz hochgradig. Massenhafte Beschläge auf der Membr. Descemeti. Tension sehr vermindert, Tris noch mehr trichterförmig eingesunken. Atropin ausgesetzt. Morph.-Inj.

16. April, Nur Handbewegungen werden noch wahrgenommen.

20. April. Bulbus immer weich, Cornea viel stärker beschlagen auf der Ruckseite. Hypopyon. - Cataplasmen.

1. Mai. Cornea sehr trüb, der vordere Theil des Bulbus vorgedrängt.

3. Mai. Nur eine Spur von Lichtschein. Die Tumoren auf der Iris nehmen rasch an Grösse zu. Bulbus weich.

5. Mai. Der ganze vordere Theil des Bulbus bis zu den Muskelansätzen ist. stark cylindrisch vorgedrängt. In der vorderen Kammer liegt vor der Iris ein braunrother Klumpen (Blutgerinnsel). Die vordere Kammer immer noeh sehr tief. 
8. Mai. Ausserhalb des unteren Hornhautrandes tritt in der Seleralzone Perforation ein.

10. Mai. Ausbuchtung des unteren Ciliargebietes viel stärker, heftige Schmerzen.

11. Mai. Ansbuchtung immer stärker. Cornea beginnt sich zu vascularisiren.

16. Mai. Kein Lichtschein mehr. Drüsen vor dem Ohr und in der Wangengrube rechts geschwollen und hart.

23. Mai. Enucleatio bulbi. Heilung normal.

28. Mai. Entlassen, vollkommen wohl.

30. Mai. Es stellt sich Kopfweh, Müdigkeit, Fieber ein. Das Fieber nimmt zu und Patientin geht unter den Erscheinungen einer tuberculösen Meningitis rasch zu Grunde.

11. Juni. Tod. - Die Section konnte leider nicht gemacht werdes.

Der Bulbus zeigt, nachdem er gehärtet und durch einen Verticalschnitt halbirt worden, ein von den beiden eben geschilderten Fällen sebr abweichendes Bild, entsprechend der Rapidität, mit welcher hier der Process sich entwickelt und abgelanfen. Auch dadurch, dass hier offenbar von vornherein hauptsächlich das Corpus ciliare Sitz der tuberculösen Entzündung war, wird der Befund stark modifieirt, abgesehen davon, dass durch die vollzogene Perforation manches sich anders gestalten musste. Der Durchmesser von der Vorderfläche der Cornea zur Hinterfläche der Sclera beträgt $29 \mathrm{Mm}$. Die Retina ist faltig abgelöst, der Glaskörper, nach vorn gedrängt, liegt in der Perforationsstelle. Die Linse ist ausgetreten. Von der Iris ist nichts mehr zu sehen. Nach oben nimmt ein grosser Tumor den Platz des Corpus ciliare und der Iris ein. Er liegt vorn der Cornea unmittelbar an, orstreckt sich nach rückwärts bis fast zum Aequator bulbi und prominirt in's Innere des Bulbus hinein bis zur Linie des erwăhnten antero-posterioren Durehmessers des Bulbus. Von vorn nach hinten (frontal) gemessen, zeigt dieser Tumor einen Durchmesser von 9,7 $\mathrm{Nm}$. Ihm entsprechend, findet sich auf der gegenüberliegenden Seite ebenfalls Iris und Corpus ciliare in einen Tumor verwandelt, der aber etwas geringeren Umfang besitzt und zum Theil schon aus der-Bulbuscapsel herans unter die Conjunctiva gedrungen ist. Innerhalb derselben endet die Sclera mit zugespitztem Rand. Die Cornea ist hochgradig verdickt. Der grösste Durchmesser derselben 
beträgt $3,4 \mathrm{Mm}$. Aber entsprechend dem oberen Rand wird sie rasch äusserst dünn und die Corneo-Scleralgrenze ist hier nur noch durch einige Faserlagen gebildet, indem der grosse Tumor dort ebenfalls beinahe zur Perforation geführt hat (vergl. Fig. $2^{*}$ ). Eine Menge Gefüsse durchziehen die Hornhant und diese, nebst einer starken Immigration von Wanderzellen und einem beträchtlichem Oedem bedingen die ausserordentliche Schwellung dieser Membran. $\mathrm{Da}$, wo die Cornea an die Perforationsstelle stösst, finden sich so viele strotzend gefüllte Gefässe nebst zahlreichen, grossen Blutextravasaten und Haufen eingewanderter Zellen, dass vom eigentlichen Gewebe der Hornhaut fast nichts mehr vorhanden ist. Sehr stark eitrig infiltrirt ist natürlich der Glaskörper.

Was nun die erwähnten Tumoren betrifft, so ist hier die tuberculöse Natur derselben hauptsächlich an zwoi Stellen nachweisbar. Erstens in der vorderen Partie des kleineren zum Theil schon nach aussen gedrungenen und in den hintersten Lagen des grösseren Tumor. Alles Uebrige ist schon grösstentheils in Zerfall and Verkäsung begriffen, was verstăndlich wird, wenn man die fast absolute Gefässlosigkeit der ganzen Geschwulst berücksichtigt. An den zwei erwähnten Stellen aber sind unzweifelhafte Tuberkelknötchen in ziemlicher Menge nachweisbar. Anch diese neigen central bäufig schon der käsigen Motamorphose $\mathbf{z u}$, besitzen aber doch in hinlänglicher Anzahl noch im Centrum eine oder mohrerer Riesenzellen.

Die ausserhalb der Tuberkelknoten liegenden Theile der Choroidea, mit anderen Worten die ganze Membran mit Ausnahme der vordersten an's Corpus ciliare grenzenden Partien. derselben, die ebenfalls noch stellenweise in das Tuberkelconglomerat mit einbezogen worden, sind frei von Miliartuberkeln. Es findet sich bloss ungemein starke Füllung der Gefăsse und diffuse, nicht heerdförmige Infiltration mit Eiterkörperchen.

Auch die Retina ist frei von Tuberkelknötchen.

*) Der Schnitt, nach dem die Zeichnung angefertigt, liegt etwas seitlich von' der Halbirungslinie des Bulbus, daher der grössere Tumor etwas kleiner ist, als die Maasse angeben. 
III. Die Chorioiditis tuberculosa chronica.

Während die bisher geschilderten Affectionen die Tuberkelentwicklung unter einem uns etwas ungewohnten Bilde präsentirten, dürfte die letzte bier jetzt noch zu besprechende Aeusserungsweise der Tuberculose im Auge wohl geeignet sein, durch die Unzweidentigkeit des anatomischen und klinischen Befundes auch die vorhergehenden Erörterungen zu bestätigen und noch mehr vor Zweifel sicher zu stellen. Wir haben hier nämlich eine Form der uns beschäftigenden Neubildung vor uns, die ganz und gar analog ist dem bekannten conglobirten Hirntuberkel.

Es handelt sich um einen äusserst interessanten Fall, in welchem zum ersten Male überhaupt die Diagnose Chorioiditis tuberculosa intra vitam gemacht, das ophthalmoskopische Bild des conglobirten Tuberkels der Chorioidea genau festgestellt, die klinische Dignität der Erkrankung ganz bestimmt präcisirt wurde und wo schliesslich die anatomische Untersuchung dies alles vollständig bestätigte.

Doch möchte ich mir vorerst noch einige allgemeine Bemerkungen über diese Affection des Auges erlauben. Die Scheidung zwischen "Tuberculose der Chorioidea" (als Theilerscheinung allgemeiner Miliartuberculose) und "Chorioiditis tuberculosa", wie sie v. Wecker*) vornimmt, scheint mir anfechtbar zu sein. Denn da bei der Miliartuberculose der Chorioidea diese Membran immer auch in höherem oder geringerem Grade sich im Zustande der Entzündung befindet, wie aus der Infiltration und der Gefässerweiterung, die sich immer um die einzelnen Miliartuberkel herum findet, hervorgeht,

*) Handbuch von Graete n. Sämisch, Bd. 4, pag. 645 . 
so dürfte wohl die Unterscheidung zwischen "miliarem" und „conglobirtem" Tuberkel der Chorioidea oder noch besser zwischen "acuter" und "chronischer tuberculöser Entzündung der Chorioidea" vorzuziehen sein. Weiss will zwar die Trennung, wie sie v. Wecker vornimmt, beibehalten, die Benennung "Chorioiditis tuberculosa" aber nur für jene Fälle gelten lassen, wo die Tuberculose primär die Urea befällt (loc. cit. pag. 140 und 41). Dies scheint mir nun ebenfalls etwas precär, denn es möchte dem Kliniker in den meisten Fällen letzterer Art schwer, ja unmöglich sein, zu constatiren, dass nicht schon anderswo im Körper des betreffenden Patienten die Tuberculose (vielleicht irgendwo in Lymphdrüsen oder auf dem Peritoneum) ihren Sitz aufgeschlagen hat. Wenn Weiss pag. 154 sagt: „im zuletzt beschriebenen Fall finden wir in fast allen' Theilen des Auges histologische Tuberkel, in keinem andern Theil des Körpers wird sonst noch eine tuberculöse Affection gefunden", so bleibt er für letzteres uns den anatomischen Beweis schuldig, da in dem betreffenden Fall der Patient nicht secirt und nur das enucleirte Auge untersucht wurde.

Auch bezüglich der Tuberculose der Chorioidea können wir im Interesse einer breiteren, klinischen Basis mit Vortheil ältere Beobachtungen herbeiziehen. So finden wir bei Chelius*) und bei v. Arlt**) eine Chorioiditis scrophulosa und tuberculosa erwähnt und von letzterem genau geschildert und mit mehreren Krankengeschichten erläutert, die, wenn auch die genauen anatomischen Untersuchungen fehlen, offenbar mit unserer hier $z u$ erörternden Affection identisch sind. v. Arlt schied zuerst diese bei „zarten, blonden, scro-

*) Chelius. Lehrbuch der Augenheilkunde. 1843. Bd. 1, pag. 242.

*) Arlt. Die Krankheiten deś Auges. 2, Bd, pag. 212 u. ff. 
phulösen Kindern" vorkommende Erkrankung der Chorioidea aus der grossen Gruppe des Be er'schen „amaurotischen Katzenauges" aus und traf mit der Benennung scrophulöse oder tuberculöse Chorioiditis nicht nur im klinischen, sondern auch im anatomischen Sinn wohl das Richtige. Denn da die suppurative Chorioiditis nicht spontan entsteht, die Form aber, welche bei Meningitis cerebrospinalis manchmal auftritt, in jenen von v. Arlt zusammengestellten Krankengeschichten jedenfalls nicht vorlag, so bleibt zur Erklärung jener Befunde bloss die durch conglobirte Tuberkel producirte Erkrankungsform übrig. Auch bei Mackenzie finden wir eine ähnliche Beobachtung erwähnt*) und ebenso bei Jakob**), welch letzterer, wie v. Arlt die scrophulöse Natur des Leidens und das gleichzeitige Vorkommen von Drüsengeschwülsten (Glandular disease) betont.

Die erste genaue mikroskopische Untersuchung eines grossen, conglobirten Chorioidaltuberkels verdanken wir v. Graefe***). Er fand die Affection zwar nicht beim Menschen-, sondern an einem Schweinsauge. Die Beschreibung des Befundes und die vortreffliche Abbildung desselben stimmen in manchen Punkten ganz mit unserem unten geschilderten Fall überein. v. Graefe äussert sich gelegentlich dieser Beobachtung folgendermassen: „Ob eine der beschriebenen ähnliche Ablagerung von Tuberkeln auf der Chorioidea vom Menschen vorkommt, ist noch nicht mit Sicherheit erwiesen; gewisse Chorioidealexsudate, welehe nicht gar selten an Kindern beobachtet werden und durch ibr Aussehen als Medullarsarcome imponiren können, wurden von Chelius und v. Arlt als Chorioiditis scrophulosa (tuber-

") loc. cit. Bd. 2, pag. 272, Obs. 468.

**) loc. cit. pag. 170 .

**) Archiv f, Ophth., Bd. II., 1. pag. 218. 
culosa) beschrieben" etc. Beim Menschen wurde erst jüngst und zwar von Weiss*) ein ähnlicher Befund constatirt (der erste seiner $3^{*}$ Fälle).

19) Heinrich M., 8/2 Jahre alt, kam am 15. Decbr. 1877 wegen einer Entzundung des linken Auges, die seit drei Monaten bestand, zu Prof. Horner. Das Ange sei geschwollen geworden, besonders nach oben-aussen, so dass das obere Lid stark hervorgestanden habe. - Der Knabe sei 8 Wochen zu früh geboren worden, sei schwächlich gewesen. Er litt im zweiten Jahr an der Halsbräune.

Patient sieht blass und etwas aufgedunsen aus. Die Untersuchung des Auges ergiebt: Conjunctiva palpebrarum leicht geröthet und geschwellt. Cornea und Iris normal. Bei Hebung des oberen Lides und Senkung des Blickes tritt nach anssen oben von der Cornea im Bereich von ea. $4 \square \mathrm{Cm}$. eine graulich - rothe', flache Wucherung der Conjunctiva bulbi zu Tage. Thre vordere Begrenzung wird durch den oberenausseren Cornealrand gebildet. Nach hinten wird sie zusehends breiter und ihre hintere Begrenzung wird durch einen in der Richtung des Aequator bulbi verlaufenden und auch nur wenig vor dem Aequator liegenden, ca. $1 / 2 \mathrm{Cm}$. langen und ca. 2 bis $3 \mathrm{Mm}$. breiten Substanzverlust, der fast wie ein rinnenförmiges Geschwür aussieht, bezeichnet. Die Ränder dieses Snbstanzverlustes, der übrigens nicht sehr tief ist, sind unregelmässig, etwas gezackt und von mehr gelbrother Färbung, während der Grund dieser Zerfallsstelle schmutzig grau - gelb aussieht. - Bei genauerer Betrachtung dieser abnormen Conjunctivalpartie bemerkt man sofort, dass ibre Oberfläche leicht höckerig ist und dass die einzelnen, kaum stecknadelkopfgrossen Höckerchen sich von dem rothen Grund durch eine mehr gran - weissliche Färbung abheben. Die ganze Wucherung hat durchweg eine Dicke von ca. $2 \mathrm{Mm}$. - Sie ist ziemlich stark vascularisirt und ganz besonders fallen einige sehr weite, dunkelrothe Gefässe auf, die von der nasalen Seite her an dieselbe herantreten und sich über dieselbe verbreiten.

Bei der ophthalmoskopischen Untersuchung (s. Fig. 6, Tafel 3) sieht man nach aussen - oben in der Peripherie der

*) loc. cit. pag. 118 . 
Chorioidea einen flachen, ausgebreiteten Tumor, ungefähr dem Meridian entsprechend, der durch die Mitte der erwähnten Zerfallsstelle in der Conjunctivalwucherung geht. Der Tumor beginnt ca. 6 Papillen breit rom Opticus. Sein Ende gegen den Aequator hin ist nicht zu sehen, er wird dort zusehends breiter. An der gegen die Papille gerichteten Grenze zeigen sich einerseits mehrere kleine, rundliche, atrophische Stellen in der Chorioidea, anderseits ein in einem Bogen verlanfender stark pigmentirter Streifen. Die Begrenzung des Tumor ist nirgends scharf, sondern zwischen demselben und dem ibrigen Augenhintergrund findet sich, anch da, wo sich der Pigmentstreif erstreckt, noch eine schmale Zone, in welcher die Chorioidea unregelmässige, leicht verminderte Pigmentirung zeigt. Der Tumor ist deutlich aus kleinen Knötchen zusammengesetzt, die eine blass-grau-röthliche Färbung besitzen, während die Einsenkungen zwisehen diesen Knötchen in Folge mässiger Pigmentirung sich grau von denselben abheben. Die Retina ist vom Tumor durch eine durchsichtige Sehicht Exsudat getrennt, liegt dem Tumor nicht unmittelbar auf, wie die parallactische Verschiebung der Gefässe nachweist. Diese sind im Bereich der Nenbildung ausserordentlich stark gefüllt und geschlängelt. Die Contouren des Opticus erseheinen leicht verwischt. Die Färbung desselben ist etwas trüb, grauroth.

An der Innenseite der linken Wade finden sich 2 Hautgeschwüre. Knochen intact.

Diagnose: Prof. Horner stellte mit aller Bestimmtheit die Diagnose auf conglobirten, d. b. aus einer Menge ron Knötchen zusammengesetzten Tuberkel der Chorioidea nebst Tuberculose der Conjunctiva. Es war nicht sowohl der flache, zahlreiche (wie Tuberkel aussehende) Knötchen enthaltende Conjunctivaltumor, als vielmebr gerade das ophthalmoskopische Bild der Chorioidalgeschwulst, das dazu führte, obige Diagnose zu stellen. Die Affection hat zwar mit dem bekannten Bild der Miliartuberculose der Chorioidea gar nichts gemein, als etwa die Färbung in einzelnen Partien des Tumors. Eine sarcomatöse Neubildung liess sich ausschliessen 1) wegen der Flachheit der Geschwulst bei gleichzeitiger, grosser Ansdehnung; 2) wegen der deutlich knōtehenförmigen Zusammensetzung derselben; 3) wegen der am Rand der Neubildung sich findenden unzweifelhaften Spuren entzündlicher Vorgänge in der Chorioidea (Lockerung der Pigmentirung, atrophische

v. Graefe's Archiv für Ophthalmologie, XXV. 4. 
Flecke, glänzende kleine Punkte, Zusammenhänfung des Pigmentes). Für die Annahme einer eitrigen Chorioiditis fehlte einmal jedes causale Moment, dann sprach gegen eine solche Entzündung auch die relatî beschränkte Localisation des Chorioidalprocesses. Die Vermuthung lag sehr nahe und wurde auch ausgesprochen, dass die Chorioidalverändernng mit der Conjunctivalaffection in unmittelbarem Zusammenhang stehe. Denn das hintere (aquatoriale) Ende der letzteren mit der erwähnten Zerfallsstelle entsprach der Lage nach genau der vorderen Partie des Chorioidaltumors. Die Conjunctivalwucherung imponirte, wenn sie auch von unseren bisherigen Befunden bei Conjunctivitis tuberculosa etwas differirte, doch ganz als Tuberkeleruption. Die knötchenförmige Zusammensetzung liess sich nicht wohl anders deuten.

So wurde denn der Fall als sehr seltene tuberculöse Affection der Chorioidea and der Conjunetiva mehrmals in der Klinik vorgestellt und besprochen.

Verordnet wurde : Fischthran, Jodkalium, Bäder und kräftige Nahrung.

15. December. Die Tuberkeleruption auf der Conjunctiva macht keine Fortschritte. Die Wucherung verkleinert sich eher etwas, indem sie dünner wird. Der Chorioidaltumor bleibt sich gleich.

30. December. Am Auge: Status idem. Das Allgemeinbefinden ist viel besser. Patient sieht nicht mehr so anämisch aus.

10. Januar 1878. $\mathrm{Da}$ in den letzten Tagen hăufig, besonders am Morgen nach dem Frühstück, Erbrechen eingetreten ist, wird Leberthran und Jodkali ganz ausgesetzt. Die knötchenförmige Infiltration der Conjunctiva zeigt eine ganz deutliche Abnahme, besonders im Dickendurchmesser. Der Chorioidaltumor hat sich nicht weiter ausgebreitet und scheint etwas flacher geworden zu sein. Der Opticus zeigt deutlicher als früher das Bild ausgesprochener Neuritis ohne beträchtliche Stauungserscheinungen (trübe grau-rothe Färbung, Contouren verwischt) und jetzt zeigt auch der rechte Opticus das Aussehen, das der linke Anfangs bot: verwischte Contouren, Farbung leicht grau-roth, keine wesentliche Schwellung.

18. Januar. Kein Erbrechen mehr, kein Kopfweh, aber häufig Müdigkeit. Keine deutlichen Cerebralsymptome. Temperatur normal. Patient hat aber seine Munterkeit ganz ver- 
loren, sitzt still, ohne zu sprechen, herum, klagt über nichts. Seit gestern giebt er hartnäckig verdrehte Antworten, die bei seinem sonst leidlichen Befinden rom Wartpersonal als Lügen taxirt werden.

19. Januar. Patient sieht elend aus, giebt mühsam Antwort, erbricht das Frühstück, liegt theilnahmlos im Bett, klagt, auch auf Befragen, über nichts, isst nicht, trinkt bloss etwas Wein. Gesicht blass, keine Lähmungserseheinungen. Brust und Abdomen zeigen nichts Abnormes. Zunge sehr belegt. Puls 100. Temp. 37,0.

20. Januar. Patient liegt mit halb geöffneten Augen apatisch da, giebt auf Befragen keine Antwort, schluckt den Wein nicht mehr, streckt die Zunge nur langsam und mühsam ein Bischen heraus; dieselbe ist stark belegt. Puls 100. Temp. Morgens 37,5, Abends idem. Respiration normal. Von Mittag an lässt Pat. Urin und Stuhl unter sich gehen.

21. Januar. Der soporöse Zustand hat zugenommen. Schlaf ruhig. Patient schluckt nicht mehr. Keine Schmerzäusserungen. Abdomen eingezogen. Pupillen mittelweit (stehen noch etwas unter Atropinwirkung). Keine weiteren Lähmungserscheinungen, keine Convulsionen. Zunahme der Staungserscheinungen an der linken Papilla optici. Die Schwellung derselben, Schlängelung und Verbreiterung der Gefässe hat zugenommen. Rechts mässige Neuritis ohne sehr hohen Grad von Staungserscheinungen. Der übrige Augenhintergrund rechts ist normal. Keine Tuberkel zu sehen. Links hat der Chorioidaitumor nicht an Grösse zugenommen, ist eher noch mehr abgeflacht. Auch die Infiltration der Conjunetiva bulbi ist flacher, blasser. Puls 120. Temp. Morgens 37,0, Abends 37,2. - Diagnose: Hirntumor und zwar Hirntuberkel, wahrscheinlich im Kleinhirn sitzend.

22. Januar. Respiration normal. Patient reagirt fast gar nicht mehr. Die Pupillen reagiren nicht auf Lichteinfall. Kein Fieber.

23. Januar. Patient stöhnt in tiefem Sopor. Keive Convalsionen. Puls 140-150. Kein Fieber.

24. Januar. Patient stöhnt hier und da. Sonst Status idem. Cegen Abend nimmt die Respiration ganz den Charakter des Cheyne-Stokes'schen Athmens an. Kein Fieber. Puls nicht mehr za zählen. Rechts hat die Neuritis zugenommen 
ohne sehr prägnante Erscheinungen der Staunug, die links dagegen viel mehr ausgesprochen ist.

25. Januar. Tod Morgens $3 \mathrm{Uhr}$. -

Section 10 Uhr Morgens, 7 Stunden nach dem Tod. Das Herz zeigt nichts Besonderes, enthält nebst den grossen Gefässstämmen ziemlich viel flüssiges Blut und Cruor. Linke Lunge normal, durchweg lufthaltig. Bronchialdrüsen nicht vergrössert. Rechte Lunge ist hinten leicht, an der Zwerchfellsseite fest adhärent. Die Pleura hinten und auf der Zwerchfellsseite mit zarten filamentösen Adhärenzen bedeckt. Keine Tuberkel. Der untere Lappen zeigt stark verminderten Luftgehalt. Bronchialdrüsen nicht vergrössert, nicht verkäst. Die Leberserosa ist da, wo sie an's Zwerchfell stösst, mit zahlreichen Adhärenzen und kleinen bindegewebigen Knötchen besetst. Leber im Uebrigen nichts Besonderes zeigend. Milz und Nieren normal. Peritoneum zeigt namentlich in der Nähe des Coecum Trübung und zahlreiche, kleine, flache, derbe Knötchen von Mohnkorngrösse, umgeben von feinen Pigmentirungen. Dazwischen zerstreut ganz feine Pigmentpunkte, manchmal in Gruppen beisammen, in grosser Menge. Ganz dasselbe Verhalten weist der seröse Ueberzug des Mesenteriums auf, während hingegen die Darmserosa frei ist von jeder $\mathrm{Ab}$ normität. Die Mesenterialdruisen in toto etwas geschwellt, aber nicht verkäst. Darmmucosa frei.

Die Gefässe der Pia stark gefüllt, Gyri ttwas abgeflacht. Starker Hydrops meningeus. Die Arachnoidea tuber Chiasma, Pons, Medulla oblongata, die ganze Unterfläche des Kleinhirns und bis in den Rückenmarkscanal hinein stark milchig getrübt und übersăt mit einer Unmasse ganz kleiner Knötchen. Im ganzen Bereich des Pons und dessen Umgebung ist sie eitrig infiltrirt, von golb-grüner Färbung und durch zahlreiche spinnegewebartige Neomembranen verdickt. Stirnlappen und Convexität bieten normale Verhältnisse der Meningen. Auf den Schläfelappen finden sich dagegen beiderseits ebenfalls ganz kleine, etwas durehseheinende Knötchen. In der Fossa Sylvii beiderseits massenhaft dieselben Knötchen, hier aber etwas grösser und deutlicher das Aussehen von Miliartuberkeln bietend. Seiten- und dritter Ventrikel sehr stark mit klarer Flüssigkeit gefüllt. In der grauen Substanz einer der unteren Windungen des rechten Schläfelappens ein über Hanfkorn grosser Knoten von gelblich - gränlicher Fürbung. Ein 
zweiter solcher, fast erbsengross, findet sich nahe dem hintern Ende des rechtor Occipitallappens an der Grenze zwischen grauer und weisser Substanz. Die graue Substanz der ganzen übrigen Hemisphäre, ebenso die weisse Substanz und die Ganglien sind frei. Blutgehalt normal. Die linke Hemisphäre zeigt normale Verhältnisse. Die obere Seite des Kleinhirns normal. Der ganze Lobus anter. inf. dext. ist dagegen vergrössert. Eine fast haselnussgrosse Partie desselben, zunächst dem Unterwurm prominirt stark und ist sehr hart. Nach hinten davon legt sich ein etwas kleinerer prominenter Kroten an. Am äusseren scharfen Rand, gleich unterhalb des Sulcus transversus zeigt derselbe Lappen einen harten Knoten, nicht sehr tief unter der Oberfläche. Die weitere Untersuchung ergiebt, dass die ganze hintere Hälfte des unteren Wurms durch einen stark kirsehgrossen Tuberkel mit gelblicher centraler Verzäsung und graulich hyaliner Randschicht eingenommen wird. Ein gleich grosser Knoten entspricht der erwähnten Prominenz am rechten Unterlappen. Ein dritter, etwas kleinerer nirmt die Randpartie desselben Lappens ein. Die linke Hälfte des Cerebellam ist frei.

Am vorderen Ende des Optieus findet sich beiderseits hinter dem Introitus sclerae eine starke ampulläre Schwellung. Der linke Bulbus wurde nach Erhärtung in Müller'scher Flâssigkeit und Alkohol so gespalten, dass die Schnittebene durch die oben erwähnte Zerfallsstelle in der Conjunctivalwucherung ging und letztere zugleich gerade halbirte. Es präsentirte sich nun das in Fig. 3 (Tafel 2) wiedergegebene Bild, das sofort eine gewisse Aehnlichkeit mit dem von Graefe (Arch. f. Ophth., Bd. 2, Taf. II., Fig. 2) rom Schweinsauge gelieferten darbot. Nur war in letzterem der Process viel weiter gediehen und unser Fall zeigt gleichsam das Anfangsstadium von jenem. Was nun zunächst auffält, ist der Umstand, dass die Hauptmasse der Neubildung ausserhalb der Sclera liegt $\left(\mathrm{T}_{2}\right.$ und $\mathrm{T}_{3}$, s. Fig. $7 \mathrm{C}$ und $\left.\mathrm{C}_{1}\right)$ und der Chorioidaltumor eine etwas geringere Mächtigkeit zeigt, ,als das ophthalmoskopische Bild erwarten liess. Vermittelst einer grossen Perforationsöffnung (Fig. 7 B.) in der Sclera stehen beide Theile der Geschwulst in unmittelbarem Zusammenhang. Die Sclera verdünnt sich gegen die Ränder der Durchbruchstelle stark. Gleich ausserhalb dieser liegt oin grosser, gelblich-grauer $9 \mathrm{Mm}$. langer und 2,5 $\mathrm{Mm}$. breiter Kăseheerd 
(Fig. 3 u. 7 K.), der fast den grössten Theil des extrabulbären Tumors einnimmt. Rings herum wird er von einer schmalen Zone grau - röthlicher Substanz umzogen (Zone der frischen Miliartuberkel) wie wir dies in ganz gleicher Weise bei den sog. conglobirten Hirntuberkeln beobachten und diese Schicht wird ihrerseits nach innen zu von der Sclera resp. der Durchbruchstelle, nach aussen hin von der stark verdickten Tenonschen Capsel, verstärkt durch verdickte und infiltrirte Züge von orbitalem Bindegewebe, begrenzt. Nach vorn gegen die Cornea zu dagegen fehlt die grau-röthliche Randschicht, es tritt dort die käsige Iasse unmittelbar auf die Oberfläche der Conjunctiva zu Tage (Fig. 7 G.): es ist dies die geschwürsartige Zerfallstelle mit schmutzig - gelblichem Grunde. Die aussere, eben geschilderte Partie der Geschwulst bietet auch bei stärkerer Vergrösserung weiter nichts Besonderes. Es hebt sich der Kranz jnnger Miliartuberkel, welcher den ganzen Käseheerd umrahmt, nach Hämatoxylintinction auf's schönste von der centralen grossen Detritusmasse ab, ein bekanntes Bild.

Betrachten wir den kleineren, intrabulbären Theil der Neubildung genauer, so können wir daran 2 Schichten unterscheiden, welche durch die fast durchweg erhalten gebliebene Glaslamelle der Chorioidea getrennt werden. Der ausserhalb, zwischen dieser Lamelle und der Sclera (resp. der Perforationsoffnung) sich ausbreitende Theil besteht aus einem Conglomerat von typischen Tuberkelknötehen. An der Perforationsstelle ist dasselbe am mächtigsten, während nach vorn und hinten die Tuberkelmasse rasch an Dicke abnimmt. Denkt man sich die Glaslamelle als Sehne zum Bogen der Sclera, so wäre also der Raum dazwischen von der Tuberkelanhäufung ausgefüllt. Diese hier befindlichen Knötchen enthalten weitaus in der Mehrzahl Riesenzellen, sind aber da und dort auch schon in centraler Necrose begriffen. In der Perforationsstelle selbst tritt die Knötchenbildung stark zurïck. Die Hauptmasse des Gewebes, namentlich nahe den Rändern der Scleralöffnung, besteht aus Granulationsgewebe, dessen Zellen die Aufgabe zuzufallen scheint, das derbe Gefüge der Sclera zu demoliren und Platz zu schaffen für die Ausbreitung der Tuberkelwucherung; es ist mit andern Worten dies das reactiv entzündliche Gewebe, das sein Dasein dem Reiz, der von der Tuberkeineubildung nach allen Seiten hin ausgetibt wird, verdankt. Diese Zellhaufen haben die Darchbruchstelle in der Sclera so stark nach beiden 
Seiten hin erweitert (auf ca. $6 \mathrm{Mlm}$. Weite), dass nicht mehr $\mathrm{za}$ entscheiden ist, $\mathrm{ob}$ die Tuberkelmassen in ihrem Vordringen nach aussen einem Gefäss gefolgt sind, wie dies die Sarcome zu thun pflegen, oder aber nicht. Wahrscheinlich war dies der Fall, wenigstens entspricht die Perforationsöffnung ihrer Lage nach ziemlich genau der Durehtrittsstelle der Vasa vortic. Kehren wir nun nochmals zur Lamina vitrea der Chorioidea zurück, so sehen wir dieselbe, wio erwähnt, nach innen hin die Tuberkelknötchen begrenzen. Sie besitzt offenbar trotz ihrer Dünnbeit eine bedentende Widerstandskraft, grösser als die Sclera, eine bekannte Eigenschaft dieser sog. elastischen Membranen. Doch zeigt auch sie an einer Stelle eine Durchbruchspforte, die jedoch nicht sehr umfänglich ist. Durch diese hindurch steht die Tuberkelanhäufung mit einer innerhalb der Glaslamelle sich ansbreitenden, pathologisehen Gewebsmasse in Zusammenhang. Diese letztere enthält aber kein einziges Tuberkelknötchen, sondern nur junges, zum Theil schon ziemlich stark organisirtes Bindegewebe, dem sich die Trümmer des Pigmentepithels beimischen. (Fig. 7 F.). Auf den ersten Blick sieht es ans, als ob die Epithelzellen dieses nengebildete Gewebe durch rege Proliferation producirt bătten. Man îberzengt sich aber leicht davon, dass die Elemente desselben von jener äussersten Zone des Tuberkelhaufens abstammen, die ich eben als reactiv entzündliche bezeichnete und deren Virchow*) als ,dichte Areola von Bindegewebe und Gefässen" Erwähnung thut. - Jene tuberkelfreie Gewebslage aber steht an einzelnen Stellen in ziemlich innigem Zusammenhang mit der ihr auf der Innenseite anliegenden Retina und zwar durch zahlreiche feine Fasern - die ausgewachsenen und verdickten Stützfasern der Netzhant - welche sich zwischen den Spindelzellen und Fibrillen jener Schicht verlieren.

Dabei ist an diesen Stellen die Structur der Retina ganz verwiseht. Die nervösen Elemente sind zu Grunde gegangen und geblieben ist bloss das bindegewebige Stützgewebe, durchsetzt von einer Menge junger Bindegewebszellen und ron Exsudatzellen. Da wo die Netzhant nicht an das innerhalb der Glaslamelle sich flach ausbreitende Gewebe geheftet ist, trennt ein ungeformtes, durchsichtiges Exsudat in nicht sehr dicker Lage die beiden Membranen. Wis enthält viele Pigment-

*) Cellularpathologie, pag. 561 . 
körner und Pigmentzellentrümmer und farblose Blutkörperchen, namentlich etwas entfernter von dem Centrum der Geschwalst. Diese leichte Ablösung der Retina von ihrer Unterlage war auch ophthalmoskopisch diagnosticirt worden. Der benachbarte Glaskörper zeigte eine nur sehr spärliche Anzahl von Wanderzellen, wie er auch ophthalmoskopiseh bis zum Tode einen ganz deutliehen Durchblick auf den Tumor gestatiet batte. Entsprechend dem ophthalmoskopischen Bild, zeigten die dem Tumor bezachbarten Partien der Chorioidea bald einen ungemein starken Pigmentgehait, indem die Stromazellen eine stärkere Pigmentirung anfweisen, bald mangelt das Pigment streckenwoise total, bald finden sich kleine Exsudatheerde zwischen den Chorioidalgefässen vertheilt.

Betrachten wir woch kurs die Tuberkeleruption in der Conjunctiva bulbi. Von der Stelle, wo der grosse Käseheerd zu Tage tritt, erstreckt sich eine Reihe von Tuberkelknötchen bis vorn an den Cornealrand (Fig. 3, $\mathrm{T}_{3}$ ). Das Epithel der Conjunetiva länft ununterbrochen über die ganze Wucherung weg, senkt sich zwischen den einzelnen Knötchen jeweilen etwas in die dort befindliche Vertiefung cin und bietet im Uebrigen nichts Auffallendes. Bezüglich der Anordnung der Knötchen ist hervorzuhoben, dass gewöhnlich eines neben dem andern, nie zwei übereinander liegen (Fig. 7, $\mathrm{C}_{1}$ ). Die Tuberkel sind ziemlich gross und ihrerseits in der bekannten Weise wieder aus kleineren Knötchen zusammengesetzt. Riesenzellen sind sehr zahlreich auch hier vorhanden. Die unter dieser Tuberkelschichte liegende Sclera zeigt nichts abnormes.

Epikrise. Da die anatomisehe Untersuchung die tuberculöse Natur der Chorioidal- und Conjunetivalgeschwulst vollauf bestätigt hat und in gleicher Weise diejenige der Kleinhirntumoren, erhebt sich jun die Frage nach dem Zusammenhang der verschiedenen bei der Section gefundenen, tuberculősen Heerde. Wo ist der primäre Käs? wo die primãre Tube culose, was ist secundär? Ich gestehe, dass mir die Menge von Muthmassungen, die sich diesbezüglich änssern und vertheidigen liessen, werthlos erscheinen, donn beweisen lässt sich nichts. Man kann nicht sagen, ob die Tuberkelknoten im Gehirn älter sind, als der im Auge. Man weiss 
nicht, wann der Patient an jener ersten Peritonitis litt, von der noch deutliche Reste zu sehen sind und die wahrscheinlich schon tuberculöser Natur war. Denn ein Theil der Knötchen auf dem Peritoneum sind fibröse Tuberkel, von vielleicht beträchtlichem Alter. Möglich wäre es ja, dass eine Fütterungstuberculose vorliegt, dass zuerst das Peritoneum in der Nachbarschaft der Aufnahmsstelle des Giftes erkrankte und dann von da aus gleichzeitig die grossen Tuberkelknoten im Gehirn und der im Auge ihre Entstehung fanden. Aber beweisen kann man es nicht.

Eines aber muss hier noch betont werden. Man könnte, was den Befund am Auge betrifft, versucht sein zu glauben, dass der Tumor von aussen nach innen vorgedrungen sei und dass nicht in der Chorioidea die Tuberkelbildung begonnen habe, weil nämlich der ausserhalb der Sclera liegende Tomor viel grösser ist und den grossen Käseheerä enthălt, wăhrend die Neubildung in der Chorioidea offenbar frischeren Datums sei, indem hier die Necrose noch nicht so weit gediehen sei. Dies anzunehmen, wäre entschieden unrichtig. Dass der äussere Tumor grösser ist, steht im Eisklang mit der Thatsache, dass bei nach aussen durchgebrochenen Geschwülsten des Auges der extrabulbäre Theil viel rascher wächst, als der intrabulbäre. Dass der äussere Theil hier eine starke centrale Necrose, den grossen Käseheerd, der Chorioidaltheil aber nur måssig starke Verkäsung zeigt, braucht offenbar nicht mit dem Alter der beiden Gebilde in strieten Zusammenhang gebracht zu werden.

Soweit das biesige Beobachtungsmaterial. Fassen wir es zusammen mit den schon früher publicirten Fällen von chronischer Tuberculose oder tuberculöser Entzündung des Auges, wobei namentlich noch 2 Fälle von Sattler*): Tuberculose des Opticus und tuberculöse Retinitis nicht $z u$ vergessen sind, so dürfen wir wohl

*) Sattler. Klin. Monatsblätter, 1877. Beilage-Heft, pag. 68 und 71. - Chiari, Med. Jahrbücher IV. 1877, beschreibt den intracraniellen Theil des Opticus. 
über die Häufigkeit dieser Affection des Auges erstaunt sein, ebenso wie gewiss mancher Chirurge erstaunt sein wird über die jetzt constatirte Häufigkeit der chronischen Tuberculose in den Knochen. Die jüngst erfolgten, so höchst interessanten und wichtigen Veröffentlichungen von Volkmann*) hierüber werfen anch auf unsere hier betrachteten Erkrankungen des Auges ein sehr willkommenes Licht.

*) „Ueber den Charakter und die Bedeutung der fungösen Gelenkentzündungen." Volkmann'sche Vorträge, Nr. 168-69. 


\section{Tafel-Erklärung.}

\section{Tafel 2.}

Fig. 1. Verticaler Schnitt durch den vorderen Theil des Bulbus von Fall Nr. 17 nach dem mikroskop. Präparat gezeichnet. Hartnack Syst: 1, Ocul. 2 und Camera loc. von Nachet.

C. Cornea.

J. oberer Theil der Iris, der Cornea anliegend.

T. Tuberkelwucherung an Stelle des unteren Theiles der Iris.

$\mathrm{T}_{1}$ Tuberkelwucherung an Stelle des Corpus ciliare.

L. Linsenreste. Die vordere Linsencapsel begrenzt in welligem Verlauf die hintere Seite des Iristumors (Hintere Capsel eröffinet bei der Präparation.)

LC. Linsencapsel.

Ch. Chorioidea.

R. Retina.

Fig. 2. Schnitt durch den ganzen Bulbus von Fall Nr. 18. Nach dem mikroskop. Präp. gezeichnet mit Camera luc. v. Nachet. Natürliche Grösse.

c. Cornea, die bei dem Uebergang in die Sclera, bei P, durchbrochen ist. Auf der gegenüberliegenden Seite droht Durchbruch.

P. Perforation der Bulbuscapsel.

T. Tuberculöse Neubildung.

Glk. Glaskörper.

Fig. 3. Bulbus von Nr. 19, halbirt.

$T_{1}$ Tuberkelinfiltrat in der Chorioidea.

$\mathrm{T}_{2}$ Tuberkelmassen, nach aussen durch die Sclera durchgebrochen, zeigen in ihrem Centrum den Käseheerd $\mathbf{K}$.

$\mathrm{T}_{z}$ Tuberkelinfiltrat in der Conjunctiva bulbi bis zur Cornea hin.

R. Retina über dem Chorioidaltumor.

P. Staungspapille.

S. Ampullare Anschwellung des Opticus durch $\mathbf{A b}$ hebung der Sehnervenscheide. 
Fig. 4. Veränderung der in die Linse eingewanderten Zellen in Fall Nr. 17. Nach dem mikroskop. Präparat gez. mit Syst. 7, Ocul. 2, Hartnack und Camera lnc. ₹. Nachet.

LC. Linsencapsel.

E. Linsenepithelzellen, in Wucherung bogriffen.

F. Stark vergrösserte, von den Capselepithelzellen abstammende Zellen.

G. Eingewanderte Zellen, die durch Aufnahme des Inhaltes der Linsenröhren eine enorme Grösse erlangt haben. Sie zeigen häufig Vacuolen.

H. Granulationszellen zwischen eigentlicher Tuberkelwuchernng and Linsencapsel, die Linse nach Arrosion der Capsel und Immigration zerstörend.

Fig. 5. Tuberkel mit centralen Kernhaufen statt einer Riesenzelle. Von Fall Nr. 5 nach dem mikroskop. Präparat mit Syst. 5 , Ocul. 2, Hartnack. Camera luc. v. Nachet.

\section{Tafel 3.}

Fig. 6. Ophthalmoskopisches (aufrechies) Bild des tuberculösen Chorioidaltumors in Fall Nr. 19. - Mässige Stauungspapille. Die Gefăsse der über dem Tumor abgelösten Netzhaut stark geschlängelt.

Fig. 7. Schnitt durch den I'umor desselben Falles (Nr. 19). Nach dem mikroskop. Präp. mit Syst. 1, Ocul. 2, Hartnack, Camera v. Nachet.

A. Tuberkelwucherung im Bereich der Chorioidea gegen die Sclera vordringend, dieselbe usurirend, so dass bei

B. Perforation der Sclera.

C. Ausbreitung der Tuberkel ausserhalb der Sclera.

$\mathrm{C}_{1}$ Tuberkelknötchen in der Conjunctiva bulbi (nach vorn bis zur Cornea sich erstreckend).

K. Käseheerd im Centrum des extraocularen Theiles des Tumors.

E. Chorioidalepithel.

F. Tuberkelfreie Schicht zwischen Tumor und Retina.

R. Retina.

S. Sclera.

H. Chorividea.

G. Spaltartige Zerfallsstelle im Käseheerd.

I. Bindegewebige Membran über dem Tumor. 
o. Grouffo's Archiz Bd XXZ, t4

$T^{\top} a f^{\circ} \mathbb{Z}$

Fig. 1. 

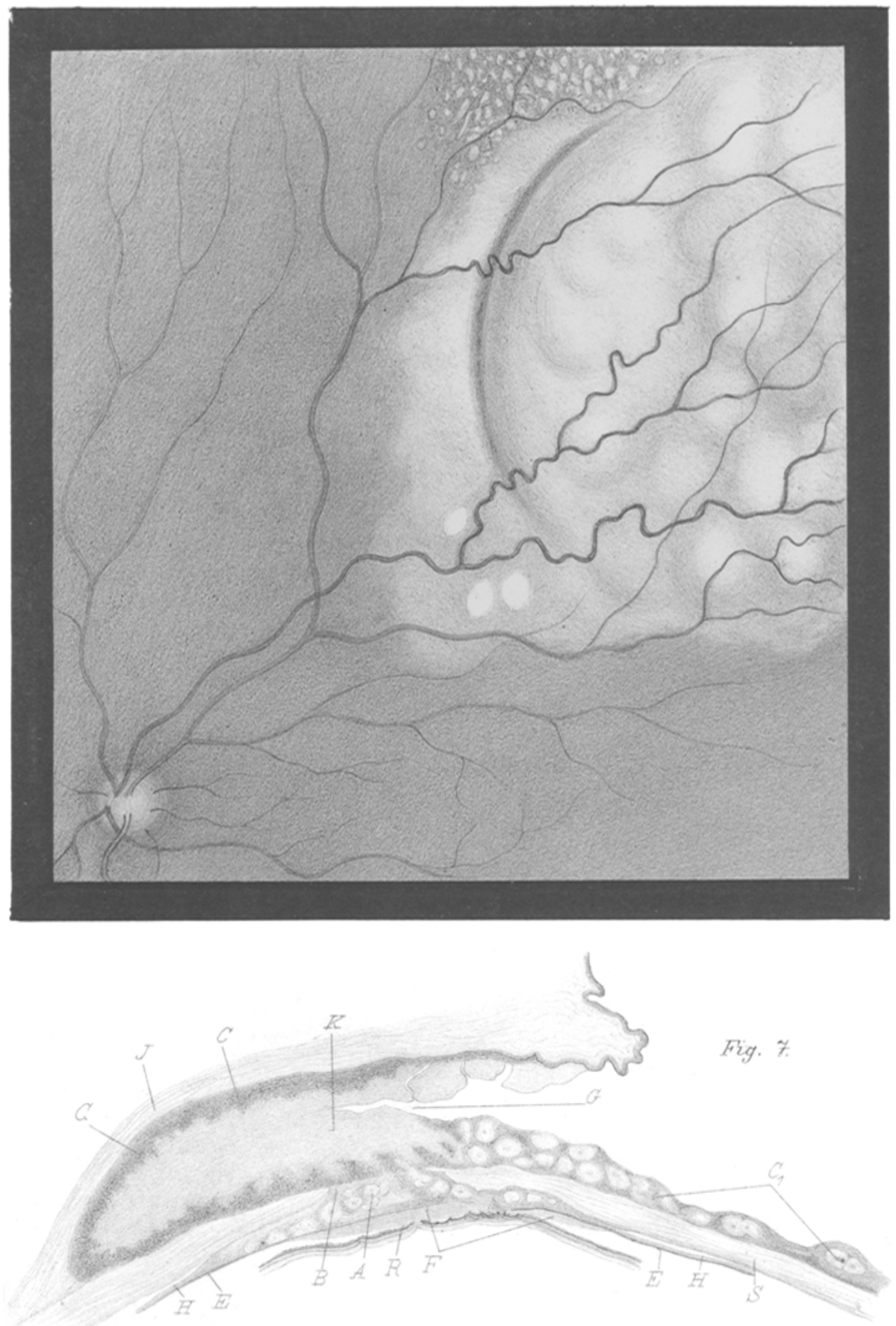

0. Haab 4ce.

Alb. Schintze Sith. Inst. Berhim 